\title{
Teams, Autonomy, and the Financial Performance of Firms
}

\author{
Jed DeVaro* \\ Department of Labor Economics \\ Cornell University \\ Ithaca, NY 14853, U.S.A. \\ Email: devaro@cornell.edu \\ (607) 255-8407 \\ August 15, 2005
}

\footnotetext{
* Thanks to The UK Data Archive for access to the data and to the following colleagues for helpful comments: Rose Batt, J.S. Butler, Tom DiCiccio, Martin Farnham, Gary Fields, Martine Haas, George Jakubson, Derek Jones, Takao Kato, David Levine, Michael Waldman, two anonymous referees, and seminar participants at Cornell University, Hamilton College, SUNY Binghamton, the Society of Labor Economists 2003 Annual Meetings, and the 2005 ASSA meetings. I am also indebted to Dana Samuelson, Robert Li, Fidan Kurtulus, David Rosenblum and Derrill Watson for comments and excellent research assistance.
} 


\title{
Teams, Autonomy, and the Financial Performance of Firms
}

\begin{abstract}
I estimate a structural model of teams, autonomy, and financial performance, using a cross section of British establishments. My findings suggest that team production improves financial performance for the typical establishment but that autonomous teams do no better than closely supervised or non-autonomous teams. I find that unobserved factors increasing the propensity to adopt teams are positively correlated with unobserved determinants of financial performance, and that unobserved factors increasing the propensity to grant teams autonomy are negatively correlated with unobserved determinants of financial performance when teams are adopted.
\end{abstract}


"Teamwork counts. If the players are equal, the will to win makes the difference. Hire the best people, emphasize teamwork, and then get them fired up to win the game."

--David Packard, Co-Founder of the Hewlett-Packard Company, cited in Packard (1996)

"Closely managed teams miss many of the advantages that internally autonomous teams can have, while possessing a number of the disadvantages. Except where concerns for internal equity are paramount, allowing teams the freedom to internally manage themselves seems to us the better strategy."

--Baron and Kreps (1999)

\section{INTRODUCTION}

It is commonly argued by both business practitioners and academicians that firms can improve their performance by using teams, as opposed to individual production, as a means of organizing the production process and that the benefits to team production may be even greater when managers grant significant autonomy to teams. A prominent textbook in strategic human resources management lists "emphasis on self-managing teams and team production" among a set of practices from which employers can choose to achieve high-commitment human resource management (Baron and Kreps 1999, page 89). The widespread touting of the virtues of team production is surprising, given the mixed results from the vast empirical literature on teams and given strong theoretical arguments suggesting that teams can have deleterious effects on labor productivity due to free-rider effects. Whether in fact the use of teams, self-managed or otherwise, affects firm performance positively or negatively in practice is an empirical question that remains open.

My goal in this paper is to identify empirically the effect of team production on financial performance in a large cross section of establishments and whether and how this effect depends on the degree of autonomy or control granted to team members. My empirical approach departs from the previous literature by estimating a structural model in which the choices of team production and team autonomy are treated as endogenous in addition to the measure of organizational performance. This is important because unobserved factors influencing these 
choices of teams and autonomy are also likely to influence organizational performance, creating biased estimates of the effects of teams if these choices are treated as exogenous right-hand-side variables as is standard in the literature.

My study is also differentiated from the previous literature by its use of financial performance as an outcome measure. The advantage of this is that financial performance is a broad measure of organizational performance that is more inclusive of the various benefits and costs of team production than are the performance outcomes that have been used previously, such as quantity and quality of outputs, efficiency, labor productivity, sales, response times, customer satisfaction, and innovation. A third distinguishing feature of my study is its use of a large, nationally-representative cross-section of British establishments, the 1998 wave of the Workplace Employee Relations Survey (WERS), as opposed to the common approach of using data from a single firm, plant, or from another narrowly-defined population. Given that the literature on the effects of teams on organizational performance is mixed, there is a clear need for work using large, nationally-representative samples to identify the effect for the typical organization. The 1998 WERS, with its questions pertaining to team production, team autonomy, firm characteristics, and recent financial performance, is ideal for this purpose.

My empirical approach consists of three steps. I first estimate the structural model, using the resulting estimates to compute for each establishment its predicted effect of teams on financial performance. Second, I rank the establishments by this measure, from the one with the lowest predicted effect of teams to the one with the highest. Third, from this ranked list of establishments I select three establishments (the one at the $25^{\text {th }}$ percentile, the median establishment, and the one at the $75^{\text {th }}$ percentile) and report the predicted effects of teams for these three establishments. For these same three establishments I then report their predicted effects of using autonomous teams, and their predicted effects of using non-autonomous teams. While my interest focuses mainly on these three treatment effects ("all" teams, autonomous teams, and non-autonomous teams) for the median establishment, I consider the other two establishments to provide a sense of how the range of benefits from team production varies in the population.

I find great diversity in the predicted effects of team production on financial performance, as would be expected given the mixed results from previous studies that typically analyze only one or a small number of organizations. Nonetheless, the positive effects occur frequently 
enough in the cross section so that the median establishment benefits considerably. This is the first principal finding of my analysis. The second principal finding is that the typical establishment enjoys no added benefit from granting teams autonomy. This finding is interesting and important because it conflicts with the conventional wisdom in the teams literature that autonomous teams generally work best and because it holds true for three different measures of team autonomy. The third finding is that the upside from team production far outweighs the downside; in other words, while the establishment at the $75^{\text {th }}$ percentile enjoys a very large predicted benefit from team production, the negative effect for the establishment at the $25^{\text {th }}$ percentile is small and statistically indistinguishable from zero. Even as low as the $10^{\text {th }}$ percentile the negative effect of team production, while statistically significant, is relatively modest in magnitude. These results suggest that team production helps the organizations it helps much more than it hurts the organizations it hurts.

Finally, my results suggest two interesting patterns of correlations among the unobserved determinants of teams, autonomy, and financial performance. First, I find that the unobserved determinants of teams are positively correlated with those of financial performance. That is, those unobserved factors that make an establishment more likely to choose teams are also likely to make that establishment a high performer. Second, unobserved factors that make autonomy more likely (given that teams are chosen) tend to lower financial performance in the presence of teams. This would suggest that establishments with autonomous teams will tend to have lower financial performance than those with non-autonomous team. My point estimates suggest precisely this result, though this difference between autonomous and non-autonomous teams is statistically insignificant. These patterns of correlations among the disturbances are interesting, and an appealing feature of the structural approach is that it allows these parameters to be estimated. These parameters are never discussed in the teams literature, since they are always implicitly restricted to be zero by the commonly-used non-structural estimation methods. The fact that these correlations are found to be large in magnitude and statistically significant in my analysis suggests the need for greater attention to the endogeneity of teams and autonomy in future work. 


\section{THEORETICAL BACKGROUND ON TEAMS AND AUTONOMY}

The economic approach to teams research evaluates the effect of team production on organizational performance by a comparison of benefits and costs, as summarized in the following simple statement by Alchian and Demsetz (1972): "Team production will be used if it yields an output sufficiently larger than the sum of separable production of [individual outputs] to cover the costs of organizing and disciplining team members." Some of the main benefits of team production accrue through productive information sharing among workers, when potential team members have knowledge that is non-duplicative and also relevant to the production process (Lazear 1995, 1998). The phrase "organizing and disciplining team members" is purposefully vague, allowing for the full range of potential costs of team production, including those associated with regular team meetings, training, and the shirking and free-riding problems discussed in the agency literature (Alchian and Demsetz 1972, Holmstrom 1982, Rasmusen 1987, Itoh 1991,1992, McAfee and McMillan 1991, Legros and Matthews 1993). ${ }^{1}$

Given that the introduction of teams is potentially associated with a variety of benefits and costs, appropriate measurement of the overall effect of teams on organizational performance requires a broad measure of organizational performance that reflects all such benefits and costs. Relying instead on the more narrowly-defined outcome variables, such as labor productivity, that are common in the empirical teams literature can yield misleading conclusions. Let us consider one example. Batt (2001) is a case study based on a sample of 230 telecommunications field technicians collected from 1993 to 1994 in a large regional Bell operating company in the United States. It combines information from survey responses, personal interviews, and data on wages and objective performance measures. The key finding is that organizational benefits from selfmanaged team production were realized because field technicians absorbed various coordination and monitoring tasks that would otherwise be assumed by supervisors, while the job performance of the technicians remained unchanged. The Batt study illustrates the value of an inclusive treatment of potential benefits and costs when evaluating the effect of teams. If the switch to self-managed teams had been evaluated only on the basis of typical measures of labor productivity or product quality, then the net benefits of teams in this company would have gone unnoticed.

\section{Definition of Autonomy}


The notion of autonomy is broad and permissive of various interpretations. Throughout this study I refer to self-managing teams and autonomous teams synonymously, defining them as teams in which the members are given the latitude to jointly decide how their work is to be done. The alternative to an autonomous team is a non-autonomous or closely-managed team, in which team members are told not only what to do but how to do it. This definition corresponds very closely to the notion of team autonomy that is used most frequently in the literature, both by economists and non-economists. In the organizational behavior literature, Hackman (1987) writes that team members are motivated when "the task provides group members with substantial autonomy for deciding about how they do the work - in effect, the group 'owns' the task and is responsible for the work outcomes." ${ }^{2}$ In the economics literature, Aghion and Tirole (1997) prefer the term "authority" to "autonomy" but their notion is also based on control over tasks or decisions about how the work is to be done. They use the definition put forth by Herbert Simon (1951) that treats authority as the right to select actions (tasks that the worker performs on the job) affecting part or the whole of an organization. ${ }^{3}$ The additional control that accompanies autonomous teams, as opposed to closely-managed or non-autonomous teams, flattens the organizational structure by reassigning decision rights to lower tiers of the hierarchy.

\section{Rationale for Granting Autonomy to Teams}

As with the employer's decision to engage in team production, the decision to grant teams autonomy is associated with costs and benefits. Eliminating supervisory roles by shifting the organizational structure from hierarchical to horizontal could reduce costs, as found in Batt (2001). On the other hand, such a shift involves a sacrifice of control by management, and it is easy to imagine contexts in which this would be undesirable (Aghion and Tirole 1997). Another potential benefit of autonomy is enhanced worker motivation as discussed in Hackman (1987). There is also evidence that in some production contexts monitoring by peers as in self-managed teams can be better than supervisory monitoring, encouraging team members to meet selfimposed group norms (Barker 1993), though again one can easily imagine contexts in which the reverse would be true, with the concerns of shirking and free riding discussed in Alchian and Demsetz (1972) even more pronounced in the absence of close monitoring by supervisors.

In economics the relevant literature concerns the delegation of authority within organizations. ${ }^{4}$ Though this subject is not always treated in the context of teams, it applies to 
teams as well as to individual workers. Grossman and Hart (1986), Hart and Moore (1990), and Hart (1995) pointed out that authority may be conferred by the ownership of an asset, which gives the owner the right to make decisions concerning the use of this asset. More generally, authority may result from an explicit or implicit contract allocating decision rights to a team or to an individual worker in the organization. An idea that emerges from this literature is that the agent's incentives are weaker when he does not have control over asset-allocation decisions. In the team context, this suggests a benefit from granting autonomy. An important contribution to this incentives-based literature is Aghion and Tirole (1997), which develops a theory of the allocation of formal authority (the formal right to decide) and real authority (the effective or de facto control over actual decision making) within organizations.

Asymmetric information is key to the Aghion and Tirole model. A principal who has formal authority over a decision or activity can always reverse the subordinate's decision but will refrain from doing so if the subordinate is much better informed and if their objectives are reasonably congruent. In the Aghion and Tirole model, there are two main benefits associated with delegating formal authority to the agent (or team in the present context). First, it credibly increases the agent's initiative or incentive to acquire information, since the granting of authority prevents the principal from over-ruling the agent in those situations in which both parties have acquired the information. Second, granting authority over decisions that matter relatively more to the agent than to the principal (an example would be performing the job standing up versus sitting down) and for which the principal's overruling might hurt the agent will make the agent more likely to participate in the contractual relationship. The main cost of delegating authority is the principal's loss of control over the choice of tasks or projects and how they are executed, potentially resulting in selection of the wrong tasks or a poor execution of the tasks selected. An increase in an agent's real authority promotes initiative but results in a loss of control for the principal. This basic tradeoff between loss of control and initiative is a central idea, and in the team context it implies that granting teams more autonomy is not necessarily better.

A related paper is Stein (2002), which is similar to Aghion and Tirole (1997) in situations in which information is "soft", meaning that the information cannot be directly verified by anyone other than the agent who produces it. But when information is "hard", or verifiable, a sharp distinction emerges between the two models. With completely hard information, there is no downside to integration in Stein's model, meaning that there is no downside to maintaining a 
hierarchical structure as opposed to delegating authority to lower levels of the organization. In his model, the fact that the agents (division managers in Stein's discussion and teams in the present context) do not have control in a hierarchical structure actually serves to heighten their incentives, as they scramble to produce enough positive information to persuade the principal (the CEO in Stein's discussion) to give them a larger share of the capital budget. Stein's paper is interesting in that it puts a more positive spin on the incentive effects of integration (as opposed to delegation of authority) than does much of the earlier literature. In the teams context this emphasizes a potential cost of granting autonomy.

Both the models of Aghion and Tirole and of Stein are concerned with incentive-based rationales for the delegation of authority, focusing on the impact of authority on the information structure of the organization. In contrast, Dessein (2002) takes the information structure as given - the agent is assumed to be better informed than the principal - and investigates how the allocation of authority affects the use of this private information, thus providing a purely informational rationale for delegation. In Dessein's model, to the extent that the principal cannot verify the claims of a better informed agent, he is in general (as long as the incentive conflict between principal and agent is not too large relative to the principal's uncertainty about the production environment) better off delegating decision rights to the agent than relying on the information he can induce from the agent's claims. Intuitively, while the agent may not tell the principal what he should do, at least the agent will use all his information when he himself makes the decision. This result suggests that centralization of authority is only optimal if top management has the information which is important to the main decisions, or is able to check and verify the information provided by lower levels of the hierarchy. The central trade-off in the model is one between a loss of control under delegation and a loss of information under communication, so delegation of authority serves as an alternative to communication of information.

The literature on communication and information processing in organizations is also relevant to the discussion of team production and sheds further light on the relative benefits and costs of delegating autonomy to teams. A number of theoretical papers (e.g. Becker and Murphy 1992, and Bolton and Dewatripont 1994) have focused on a tradeoff between worker specialization and communication. When workers are specialized in their ability to process certain types of information, a greater degree of (costly) communication is needed to coordinate 
their activities. By repeatedly processing the same type of information, a worker can lower his unit-cost of processing that information type. In the Bolton and Dewatripont model this is the main reason why a group of several specialized workers want to work together and process information as a team within the organization. In this model, to economize on overall communication costs and avoid unnecessary duplication, an efficient network must have a centralized design with a pyramidal structure. An implication of the model is that delegation of tasks or items (i.e. granting autonomy to teams in the present context) by a manager in any layer of the communication network to subordinates at lower levels only arises as a consequence of the manager's "work overload." If the manager is not overloaded, he does not delegate the work to lower levels of the hierarchy. The intuition is that information must reach the top of the organizational pyramid from lower levels, and an efficient communication network minimizes the number of workers through which a piece of information must pass. So a cost to the organization of delegation is that it increases the number of layers through which a piece of information must transit en route to the top.

Garicano (2000) is another study in the information processing literature concerned with coordination problems in the presence of specialization. Garicano focuses on the organization of knowledge in production, and assumes that the organization faces a key trade-off between communication and knowledge acquisition costs. Unlike Bolton and Dewatripont in which the organizational objective is information processing in an environment of "information overload", here it is knowledge acquisition. The model treats the role of hierarchical organization in solving problems encountered in production, with the role of supervisors being to transmit their knowledge about particularly difficult problems to production workers in the form of directions about what to do in these unusual circumstances. As in the Bolton and Dewatripont model, the optimal organization has a pyramidal shape with the production workers at the base and with few workers at higher levels acquiring knowledge about exceptional or difficult problems. In both models communication flows vertically.

A key point to take away from this discussion of the delegation of decision-making authority, and in this context the granting of autonomy to team members, is that economic models focus on tradeoffs. That is, there are both costs and benefits to the delegation of more authority, meaning that there is some optimal level and it is not true that more autonomy is necessarily better. In some production contexts autonomous teams may be desirable while in 
others closely-managed team structures are preferred. The question of whether more or less team autonomy is desirable for the median workplace must be answered empirically and is one of the goals of this paper. I now turn to a discussion of prior empirical work on teams, autonomous or otherwise.

\section{PREVIOUS EMPIRICAL WORK ON TEAMS}

Much of the vast empirical literature on the effects of teams has originated outside of economics, and an extensive review can be found in Cohen and Bailey (1997). The costs of team production tend to receive less emphasis in this literature than in economics. The dependent variables in such studies are from three main groups: organizational performance outcomes (e.g. quantity and quality of outputs, efficiency, labor productivity, sales, response time, wages, customer satisfaction, innovation); team member attitudinal outcomes (e.g. employee satisfaction, commitment, trust in management); and behavioral outcomes (e.g. worker absenteeism, turnover, safety). A review of this literature suggests that when the outcome variable is a measure of worker attitudes or behavioral outcomes, teams (particularly autonomous teams) generally have a positive effect. When the outcome variable is a measure of organizational performance, however, the results for teams and autonomy are mixed, with some studies yielding positive effects, some negative, and some no effect (Cohen and Bailey 1997). It would appear that the commonly-held view that teams (particularly autonomous teams) are beneficial is driven by outcome measures other than organizational performance; if attention is restricted to measures of organizational performance, the effect of teams (autonomous or otherwise) remains an open question.

In empirical work by economists, only measures of organizational performance have been considered as outcomes, most frequently measures of labor productivity and product quality. The well-known study of HRM systems in steel finishing lines by Ichniowski, Shaw, and Prennushi (1997) considered teams as one of a number of HRM practices used, though their focus was on HRM systems more generally rather than teams specifically. Studies for which teams were the major focus have used samples of law firms or medical partnerships, experimental data, manufacturing or service firms, seamstresses, and managers in an Argentinian bank (Boning, Ichniowski, and Shaw 2003; Hamilton, Nickerson, and Owan 2003; Liberti 2003; Encinosa, Gaynor, and Rebitzer 2000; Hansen 1997; Nalbantian and Schotter 1997; Gaynor and 
Gertler 1995; Leibowitz and Tollison 1980). By using labor productivity as the outcome variable these studies account for some of the main costs of team production, such as shirking, that are reflected in specific measures of labor productivity. Other costs that teams impose on the production process that are not directly captured by labor productivity measures will be missed. Finding evidence that teams enhance labor productivity or product quality is not, by itself, reason to use teams.

My empirical work in this paper is guided by the economic approach to teams research in two ways. ${ }^{5}$ First, I use an organizational outcome measure that is closely related to profit, thereby accounting for the full spectrum of benefits and costs of teams. Second, I treat both team production and autonomy as endogenous. Whether to organize production in teams and whether to grant such teams autonomy are choices made en route to profit maximization. In any empirical analysis there will inevitably be unmeasured factors determining organizational performance and the choices to organize production in teams or self-managed teams. If such unobserved factors are correlated, as some surely must be, then regression coefficients on choice variables such as "teams" are biased and do not capture the treatment effects of interest.

\section{DATA AND DESCRIPTIVE EVIDENCE}

The data are from the management questionnaire in the 1998 wave of the British Workplace Employee Relations Survey (WERS), jointly sponsored by the Department of Trade and Industry, ACAS, the Economic and Social Research Council, and the Policy Studies Institute. Distributed via the UK Data Archive, the WERS data are a nationally representative stratified random sample covering British workplaces with at least ten employees except for those in the following 1992 Standard Industrial Classification (SIC) divisions: agriculture, hunting, and forestry; fishing; mining and quarrying; private households with employed persons; and extra-territorial organizations. Some of the 3192 workplaces targeted were found to be out of scope, and the final sample size of 2191 implies a net response rate of $80.4 \%$ (Cully et al., 1999) after excluding the out-of-scope cases. Data were collected between October 1997 and June 1998 via face-to-face interviews, and the respondent manager was usually the most senior manager at the workplace with responsibility for employment relations. 


\section{Financial Performance}

The outcome variable I use is a discrete indicator of financial performance. The respondent manager is asked how the current financial performance of the workplace compares to that of others in the same industry. Responses include: "A lot better than average", "Better than average", "About average for industry", "Below average", "A lot below average", and "No comparison possible." A potential disadvantage of this measure is that the notion of financial performance is subject to multiple interpretations. Fortunately, an advantage of the 1998 WERS over earlier waves of the survey is that it includes an immediate follow-up question asking the respondent to choose which of several concepts corresponds most closely to his or her interpretation of financial performance. The frequency of responses is as follows: ${ }^{6}$

\section{Frequency of Responses for Interpretation of Financial Performance}

\begin{tabular}{||l|c|c||}
\hline Interpretation of "Financial Performance" & Number of Workplaces & $\begin{array}{c}\% \text { of } \\
\text { Workplaces }\end{array}$ \\
\hline Profit or Value Added & 952 & 52.9 \\
\hline Sales, Fees, Budget & 374 & 20.7 \\
\hline Costs or Expenditure & 389 & 21.6 \\
\hline Stock Market Indicators (eg. Share Price) & 54 & 3.0 \\
\hline Other Specific Answer & 31 & 1.7 \\
\hline Total & 1800 & 100.0 \\
\hline
\end{tabular}

None of the earlier waves of WIRS (the predecessor of WERS) contained this follow-up question on the interpretation of financial performance. Using the 1980 and 1984 waves of WIRS, Machin and Stewart (1990) used the same financial performance measure in their study of the relationship between unions and financial performance. In Machin and Stewart (1996) they again used the measure in a follow-up study using the 1990 wave of WIRS. Absent any information about the interpretation of financial performance in their data, the authors argued that use of the measure could still be justified on the grounds that it "reflects what managers actually consider to be financial performance and, even if this is a mixture of various indicators like accounting profits, productivity, and cash flow, this is of considerable interest in itself." (Machin and Stewart 1990, p. 330). Since the 1998 wave of the survey contains information on the exact interpretation of this question, I restrict my analysis to the subsample of employers that interprets financial performance as synonymous with profit. The composition of this subsample 
by industry is displayed in the upper panel of Table 1, using twelve industry categories in the 1992 SIC.

An advantage of using an indicator of profit as the dependent variable, as opposed to other measures of performance such as labor productivity and product quality that have been commonly used in previous work, is that profit is net of all costs. The fact that the WERS measure is subjective offers both advantages and disadvantages relative to "objective" measures of profit. $^{7}$ The main concern with a subjective measure is the potential for reporting error. The fact that the responses are skewed heavily to the right, with very few respondents reporting financial performance below average, might be cited as evidence of reporting error. However, as noted by Machin and Stewart in their work with this variable, skewness in the distribution of responses does not present problems unless it is systematically associated with the variables of interest (teams and autonomy in this context). It is also worth noting that even "objective" profit measures are associated with various measurement errors. Since accounting profits and pricecost margins are easily manipulated, at some level all such measures are subjective rather than objective. Furthermore, any incentive an organization may have to strategically overstate or understate accounting profits in its financial statements is absent in the WERS survey, in which each establishment in the sample is anonymous. Much of the error that plagues the financial performance measure is probably a consequence of imperfect information on the part of the respondent, though it is hoped that in most cases the most senior manager at the establishment would be knowledgeable about the industry and have a good sense of how her establishment's productivity and product quality stand relative to that of the competition.

Finally, an establishment's inclusion in the sample is conditional on its being operational, and length-biased sampling arises when operational establishments are sampled at a point in time. High-performing establishments have long durations of operation and are more likely to be sampled than low-performing establishments with low durations of operation. The pronounced asymmetry in reported performance that is observed in the data is therefore not surprising. ${ }^{8}$ In summary, I argue that despite the concerns about potential reporting error that plague all subjective measures, the WERS financial performance measure is interesting and worthy of study, particularly given that it is available for a large cross section of establishments, and given the clarifying question that restricts the interpretation of financial performance to mean profit. 


\section{Teams and Autonomy}

The 1998 wave of the WERS, in contrast to the earlier waves, asks a number of questions about teams. The respondent manager is asked to report the proportion of employees in the largest occupational group at the workplace that works in formally designated teams. Responses are in the following discrete categories: "All 100\%", "Almost all 80-99\%", "Most 60-79\%", "Around half 40-59\%", "Some 20-39\%", "Just a few 1-19\%", "None 0\%". An advantage of this survey question is that it specifically refers to "formally designated" teams. This precise wording of the question should direct the respondent's attention to situations of true joint production and should reduce the respondent's likelihood of reporting the use of team production simply on the basis of a cooperative or friendly atmosphere of "team spirit" at the workplace. A drawback of the survey question is that it is restricted to the largest occupational group at the establishment. The sample may contain establishments in which team production is heavily used in occupational groups other than the largest, yet the response to this question might be "None $0 \%$ ". This measurement issue is one limitation of the study.

The survey also contains three measures of team autonomy. For establishments that report the use of formally designated teams in the largest occupational group, the respondent manager is asked to respond "Yes" or "No" to the following statements:

1) "Team members jointly decide how the work is to be done."

2) "Team members are able to appoint their own team leaders."

3) "Teams are given responsibility for specific products or services."

The first of these measures comes nearest to the broad notion of autonomy that is discussed in the self-managed teams literature (Aghion and Tirole 1997, Hackman 1987). The key distinguishing feature of an autonomous or self-managing team is that team members are granted discretion over how their work is to be done. In contrast, closely-managed or non-autonomous teams are given tasks and told not only what to do but how to do it. While the main focus in this paper is on the first autonomy measure, I also report results using the two alternative measures.

Since both the team and autonomy variables are defined in terms of the establishment's largest occupational group, I provide the distribution of the analysis sample by largest occupational group in the lower panel of Table 1. All observations in the WERS are coded according to SOC codes, and I aggregated these to produce the nine one-digit categories. 


\section{Unconditional Associations Between Teams and Financial Performance}

Table 2 displays cell counts and the distribution of financial performance categories by the percentage of an establishment's workers in the largest occupational group that engages in teams. The lower panel re-displays the information from the upper panel as percentages of the column sums. Inspection of the unconditional tabulation suggests that performance and team production are positively related. Comparing the last column of the lower panel to the first, one sees that universal use of team production is associated with higher financial performance than is the absence of team production, though this increase is not monotonic as revealed by the other columns. A chi-square test of independence yields a Pearson's chi-square statistic of 47.8 that, under the null of independence, has a chi-square distribution with 24 degrees of freedom. The associated p-value is 0.003 , providing strong evidence against the null that the team production and financial performance classifications are independent of each other.

Restricting our attention to those establishments that use teams and that grant teams autonomy by allowing team members to jointly decide how the work is to be done, cell counts and column percentages are given in Table 3 for a total of 452 observations. Again comparing the last column of the lower panel to the first, it appears that universal use of team production in the largest occupational group is associated with higher financial performance, though the intervening columns reveal that the relationship is not monotonic. The Pearson's chi-square statistic for the test of independence is 29.6 , to be referred to the chi-square distribution with 20 degrees of freedom. The associated p-value is 0.077 . Hence, the null that the autonomous teams and financial performance classifications are independent can be rejected at the ten percent level but not at the five percent level.

The descriptive evidence suggests a positive relationship between team production and self-managed team production on financial performance. However, inferences based on such tabulations can be misleading since they are unconditional, and the story might look quite different after controlling for omitted firm characteristics. Furthermore, the possibility of correlated unobserved determinants of financial performance and of the choices of teams and autonomy suggests the need for a structural approach. I address these concerns in the next section. 


\section{STRUCTURAL MODEL OF TEAM CHOICE AND TEAM AUTONOMY}

The theory discussed in Section II predicts that profit is determined by whether or not production is organized in teams and, when team production is chosen, on the extent to which teams are granted autonomy. Whether teams are chosen and whether teams are granted autonomy are both endogenous variables. Establishments that use teams and grant them autonomy may have other unobservable characteristics that are correlated with the use of teams and that affect financial performance. For example, it might be that good workers go to work in profitable establishments and that establishments with good workers choose to use team production. Other examples of such unobserved variables include managerial personality and talent, and firm-specific conditions, institutions and procedures. Given the correlations between the unobserved determinants of financial performance and of the decisions to use teams and grant them autonomy, a structural model is needed that treats all three variables as endogenous.

Due to the small counts in many of the cells in Tables 2 and 3, some aggregation is needed before proceeding to multivariate analysis. I therefore focus on the decision to use teams or not, rather than on the actual fraction of the largest occupational group that participates in teams. ${ }^{9}$ That is, I construct the following binary variable:

TEAMS $=1$ if positive fraction of workers in the largest occupational group is in teams $=0$ otherwise

The autonomy dummy, AUTO, equals 1 if team members jointly decide how the work is to be done. I also present results using the two alternative definitions of team autonomy.

Since relatively few establishments report below-average financial performance, I consider only three categories rather than five, aggregating responses as follows:

FINPER $=1$ if financial performance is "About average for industry" or below $=2$ if financial performance is "Better than average" $=3$ if financial performance is "A lot better than average"

For each of these categories, Table 4 displays the sample frequencies for the choices of "no teams", "non-autonomous teams", and "autonomous teams." I provide this information both for 
the analysis sample (that is, those establishments that interpret financial performance to mean profit) and for the full sample. For each of the three measures of autonomy, the distribution of choices of teams and autonomy by financial performance is roughly similar between the full sample and the analysis sample. This provides some assurance that establishments for which financial performance is interpreted as profit do not make systematically different choices of teams and autonomy than do establishments with other interpretations of financial performance. In other words, it is unlikely that my decision to restrict the sample induces an endogenous selection bias.

The model has the following sequence. The employer first decides whether or not to organize production in teams. If teams are chosen, the employer then decides whether to grant autonomy to team members. Finally, the resulting financial performance or profit depends on the choices of teams and autonomy.

Let $\mathrm{TEAMS}_{\mathrm{i}}{ }^{*}$ be a latent index measuring the $\mathrm{i}^{\text {th }}$ establishment's propensity to organize production into teams. This propensity is determined by a vector of firm characteristics, $\mathbf{X}_{2 \mathrm{i}}$. Assuming a linear functional form we have:

$\mathrm{TEAMS}_{\mathrm{i}}^{*}=\mathbf{X}_{2 \mathrm{i}} \boldsymbol{\beta}+\boldsymbol{\varepsilon}_{2 \mathrm{i}}$

The following binary realization of this latent index describes whether team production is used:

$$
\begin{aligned}
\text { TEAMS }_{\mathrm{i}} & =1 \text { if } \text { TEAMS }_{\mathrm{i}}^{*}>0 \\
& =0 \text { otherwise }
\end{aligned}
$$

Let $\mathrm{AUTO}_{\mathrm{i}}{ }^{*}$ be a latent index measuring the $\mathrm{i}^{\text {th }}$ establishment's propensity to grant autonomy to team members. This index is determined by a vector of firm characteristics, $\mathbf{X}_{3 \mathrm{i}}$. Assuming a linear functional form we have:

$$
\mathrm{AUTO}_{\mathrm{i}} *=\mathbf{X}_{3 \mathrm{i}} \gamma+\varepsilon_{3 \mathrm{i}} \quad \text { if } \mathrm{TEAMS}_{\mathrm{i}}=1 .
$$

The following binary realization of this latent index is a censored indicator for whether or not the $\mathrm{i}^{\text {th }}$ establishment grants teams autonomy, given that teams are used at all:

$$
\mathrm{AUTO}_{\mathrm{i}}=1 \text { if } \mathrm{AUTO}_{\mathrm{i}}^{*}>0 \text { and } \mathrm{TEAMS}_{\mathrm{i}}^{*}>0
$$




$$
=0 \text { if } \mathrm{AUTO}_{\mathrm{i}}^{*} \leq 0 \text { and } \mathrm{TEAMS}_{\mathrm{i}}^{*}>0 .
$$

Let FINPER $_{i}{ }^{*}$ be a latent index measuring the financial performance of the $i^{\text {th }}$ establishment relative to that of others in the same industry. This variable is a function of firm characteristics and, in the event that team production is chosen, also of team autonomy. Assuming a linear functional form we have:

$$
\begin{array}{rlrl}
\text { FINPER }_{\mathrm{i}}^{*} & =\alpha \text { AUTO }_{\mathrm{i}}+\mathbf{X}_{1 \mathrm{i}} \boldsymbol{\delta}_{1}+\varepsilon_{1 \mathrm{i}} & & \text { if TEAMS } \\
& =\mathbf{X}_{1 \mathrm{i}} \boldsymbol{\delta}_{2}+\varepsilon_{0 \mathrm{i}} & & \text { if TEAMS } \\
\mathrm{T} & =0
\end{array}
$$

The observed discrete realization of this latent index is given by:

$$
\begin{aligned}
\text { FINPER }_{\mathrm{i}} & =1 \text { if } \text { FINPER }_{\mathrm{i}}^{*}<0 \\
& =2 \text { if } 0 \leq \text { FINPER }_{\mathrm{i}}^{*}<\mathrm{c} \\
& =3 \text { if } \text { FINPER }_{\mathrm{i}}^{*} \geq \mathrm{c} .
\end{aligned}
$$

The full specification of the structural model is as follows:

$$
\begin{aligned}
& \begin{array}{rlrl}
\text { FINPER }_{\mathrm{i}}^{*} & =\alpha \text { AUTO }_{\mathrm{i}}+\mathbf{X}_{1 \mathrm{i}} \boldsymbol{\delta}_{1}+\varepsilon_{1 \mathrm{i}} & & \text { if TEAMS } \\
& =\mathbf{X}_{1 \mathrm{i}} \boldsymbol{\delta}_{2}+\varepsilon_{0 \mathrm{i}} & & \text { if TEAMS } \\
& =0
\end{array} \\
& \text { TEAMS }_{\mathrm{i}} *=\mathbf{X}_{2 \mathrm{i}} \boldsymbol{\beta}+\varepsilon_{2 \mathrm{i}} \\
& \mathrm{AUTO}_{\mathrm{i}}{ }^{*}=\mathbf{X}_{3 \mathrm{i}} \gamma+\varepsilon_{3 \mathrm{i}} \quad \text { if } \mathrm{TEAMS}_{\mathrm{i}}=1 \\
& \text { FINPER }_{\mathrm{i}}=1 \text { if } \text { FINPER }_{\mathrm{i}} *<0 \\
& =2 \text { if } 0 \leq \text { FINPER }_{\mathrm{i}}^{*}<\mathrm{c} \\
& =3 \text { if } \text { FINPER }_{\mathrm{i}} * \geq \mathrm{c} \text { where } \mathrm{c}>0 \\
& \text { TEAMS }_{\mathrm{i}}=1 \text { if } \text { TEAMS }_{\mathrm{i}} *>0 \\
& =0 \text { otherwise } \\
& \mathrm{AUTO}_{\mathrm{i}}=1 \text { if } \mathrm{AUTO}_{\mathrm{i}}^{*}>0 \text { and } \mathrm{TEAMS}_{\mathrm{i}} *>0 \\
& =0 \text { if } \mathrm{AUTO}_{\mathrm{i}}^{*} \leq 0 \text { and } \mathrm{TEAMS}_{\mathrm{i}} *>0
\end{aligned}
$$

A simpler way to treat teams and autonomy as endogenous in the model would involve one equation for financial performance with two dummy endogenous treatments on the righthand side (one for "autonomous teams" and the other for "non-autonomous teams", with "no teams" as the reference group). The model I estimate is less restrictive than this, since it allows the teams treatment to interact with all of the other determinants of financial performance, be they observed or unobserved. ${ }^{10}$ Previous empirical work suggests the importance of allowing for interactions between teams and other determinants of organizational performance, such as other workplace practices. For example, previous work by McNabb and Whitfield (1997) showed that 
the impact of team working varied when interacted with unionization and forms of flexibility. Some of these interactions are directly estimated in my model given that, for example, several unionization variables appear in both financial performance equations. Furthermore, theory would suggest that the impact of team working would depend on, for example, the usage of different types of performance-related pay (especially individual versus team-based). This is just one example of a potentially relevant interaction of "teams" with a variable that is not explicitly included in the model and is therefore reflected in the disturbance terms. An appealing feature of the structural model is that, in treating financial performance as a switching regression, it accounts for all such interactions with the treatment effect, even for variables that are omitted or are inherently unobservable. The resulting treatment effects will be heterogeneous, depending on the values of all of the exogenous variables.

I include a common set of controls in $\mathbf{X}_{\mathbf{1}}, \mathbf{X}_{\mathbf{2}}$, and $\mathbf{X}_{\mathbf{3}}$, and in addition each equation has some covariates unique to it. See the Appendix for the specification of the covariates in each equation and for variable definitions. Finally, as is conventional in simultaneous equation models of this type with discrete endogenous variables, I assume that the joint distribution of the disturbances is multivariate normal. That is, $\left(\varepsilon_{0}, \varepsilon_{1}, \varepsilon_{2}, \varepsilon_{3}\right) \sim \mathrm{N}(\mathbf{0}, \boldsymbol{\Sigma})$. The vector of parameters to be estimated, $\boldsymbol{\theta}$, includes $\boldsymbol{\alpha}, \boldsymbol{\delta}_{1}, \boldsymbol{\delta}_{2}, \mathrm{c}, \boldsymbol{\beta}, \boldsymbol{\gamma}, \sigma_{02}, \sigma_{12}, \sigma_{13}$, and $\sigma_{23}$, where the notation $\sigma_{\mathrm{ij}}$ stands for $\operatorname{cov}\left(\varepsilon_{\mathrm{i}}, \varepsilon_{\mathrm{j}}\right)$. I estimate the equations jointly by maximum likelihood, as described in the Appendix.

\section{Identification}

Identification is facilitated through some exclusion restrictions on the exogenous variables. The variable excluded from the financial performance equation and used to identify the use of teams is the indicator for "just-in-time" production. That is, I assume that just-in-time technology directly affects whether work is organized in teams but affects financial performance only indirectly through its effect on teams. A review of the teams literature provides a clear justification for the presence of just-in-time in the teams equation, since just-in-time is frequently cited as an important determinant of the decision to use team production. For example, as argued by Berg et al. (1996) in the context of the apparel industry, the demands of just-in-time production require flexible organizational structures such as teams. More recently, Hamilton, Nickerson, and Owan (2003) cite the demand by retailers for just-in-time production as a major 
reason for the introduction of teams during 1995-1997 in the garment manufacturing establishment they study.

Just-in-time has not been central to discussions of financial performance in the empirical literature. ${ }^{11}$ Its exclusion from the financial performance equation, however, is potentially problematic. Given that financial performance (interpreted as profit) is one of the broadest measures of organizational performance available, virtually any exclusion restriction is open to the critique that it could have some effect on financial performance that operates directly rather than through the channel of team production. Furthermore, just-in-time is frequently cited in the literature as part of a total quality management program, with claims for a lot of organizational benefits. While some of these elements of just-in-time and total quality management are complementary to teams, team production does not imply just-in-time. This suggests a potential direct effect of just-in-time on financial performance, as opposed to its indirect effect on performance through teams. The restriction that just-in-time does not enter either of the financial performance equations clearly cannot be rejected at conventional levels of significance, on the basis of a likelihood ratio test ( $\mathrm{p}$-value $=0.565)$, and for this reason I maintain it. While this statistical evidence supports the restriction, the theoretical rationale for a possible direct effect of just-in-time must be acknowledged and suggests some degree of caution in interpreting the results.

The decision over whether to allow teams autonomy or not is identified from a set of four variables, unique to the autonomy equation, that proxy for the organizational and informational structure of the establishment, the alignment of incentives between workers and owners, and the importance to the employer of monitoring inputs. The first three of these are qualitative measures of managerial opinion. The respondent manager is asked to comment on each of a list of statements, responding with "Strongly agree" (1), "Agree" (2), "Neither agree nor disagree" (3), "Disagree" (4), or "Strongly disagree" (5). The questions of interest as determinants of team autonomy are as follows:

Information: "Those at the top are best placed to make decisions about this workplace." Incentive Alignment: "Employees here are fully committed to the values of this organization." 
Decisions: "Most decisions at this workplace are made without consulting employees."

The fourth variable unique to the autonomy equation is the proportion of workers at the establishment that ever work from home during normal working hours, reflecting the importance to the employer of monitoring inputs. Responses include: "Half or more 50\%+" (1), "A quarter up to a half 25-49\%" (2), "Up to a quarter 10-24\%" (3), "A small proportion 5-9\%" (4), "Hardly any (less than 5\%)" (5), or "None 0\%" (6).

The theoretically predicted signs of the effects of these variables, ceteris paribus, on the propensity to grant teams autonomy are as follows. In establishments where the production process is such that top managers are better equipped or have better information for making decisions than workers on the line, autonomy is less likely to be granted to teams. Therefore, "Information" and "Decision" should both have positive effects, meaning that employers who disagree with those statements are more likely to grant autonomy. In establishments where the interests and goals of workers are aligned with those of the employer, autonomy is more likely to be granted to teams. ${ }^{12}$ Therefore "Incentive Alignment" should have a negative sign, since agreement with the statement is associated with more autonomy (Aghion and Tirole 1997). The fraction of employees who work at home might be thought of as a proxy for the importance the employer places on monitoring workers through direct supervision, as opposed to relying on the social norms and peer pressure that arise in a team context. Therefore, the expected sign on this variable is negative, meaning that workplaces that are more permissive of working from home are more likely to grant team autonomy.

I maintain the strong assumption that these four variables do not determine teams and that they determine financial performance only through their effects on team autonomy. Again, given the broad nature of the dependent variable, virtually any exclusion from the financial performance equation is subject to the critique that it might have a direct effect and should therefore be included. My approach is therefore to select a set of variables that, while clearly important in determining autonomy, are arguably much less important in determining teams and directly determining financial performance. I then consider statistical tests of the validity of these restrictions. The entire set of exclusion restrictions in the structural model cannot be rejected on the basis of a likelihood ratio test ( $\mathrm{p}$-value $=0.338$ ). While the exclusion restrictions cannot be collectively rejected, if we focus attention only on the four restrictions that omit the 
additional autonomy variables from the teams equation the statistical evidence favoring these exclusions is somewhat weaker. It remains true that these exclusions (considered in isolation) cannot be rejected at the five percent level on the basis of a likelihood ratio test, though they can now be rejected at the ten percent level $(\mathrm{p}$-value $=0.054)$. The fact that these exclusions are accepted only marginally at the five percent level is perhaps not surprising, since from a theoretical perspective most factors that would lead a firm to grant autonomy (given a choice of teams) might be expected to have at least some influence on the decision to adopt teams. Nonetheless, since the exclusions cannot be rejected at the five percent level I maintain them, though theoretical rationales for these variables potentially having direct effects on either teams or financial performance suggest some degree of caution in interpreting the results.

In addition to these economic issues of identification, the statistical model requires some standard identifying restrictions on the covariance matrix, due both to the discrete nature of the endogenous variables and to the fact that part of the system is a switching model with endogenous switching. Since each of the endogenous variables is observed only discretely, I normalize the diagonal elements of $\Sigma$ to one. Furthermore, the parameter $\sigma_{01}$, or $\operatorname{cov}\left(\varepsilon_{0}, \varepsilon_{1}\right)$-the covariance between the unobserved determinants of financial performance when teams are used and the unobserved determinants of financial performance when teams are not used -- is not identified because for each observation financial performance is observed in only one of the two states $(T E A M S=1$ or $T E A M S=0)$. I therefore impose the restriction $\sigma_{01}=0$, as is standard in switching regression models. Though such a restriction is necessary, it might not be innocuous since, for example, it implies that there are no common shocks to financial performance across geographic locations.

The parameter $\sigma_{03}$, or $\operatorname{cov}\left(\varepsilon_{0}, \varepsilon_{3}\right)$ - the covariance between unobserved determinants of financial performance when teams are not chosen and unobserved determinants of autonomy - is also not identified because the financial performance equation conditional on "no teams" being chosen is never observed in conjunction with the autonomy choice. Some restriction is therefore required, and again I fix this parameter to zero. This restriction might be problematic if, for example, some workplaces have greater monitoring ability and this is correlated both with financial performance and with the willingness to allow autonomy to teams. While restrictions such as $\sigma_{01}=0$ and $\sigma_{03}=0$ are necessary, given the available data, they should not be viewed as extending beyond the standard restrictions imposed in teams research. The standard approach is 
to treat both teams and autonomy as exogenous variables on the right-hand-side of some equation for organizational performance. This approach implicitly imposes not only $\sigma_{01}=0$ and $\sigma_{03}=0$, but additionally $\sigma_{13}=0, \sigma_{23}=0, \sigma_{12}=0$, and $\sigma_{02}=0$. That is, the unobserved determinants of autonomy are assumed uncorrelated with the unobserved determinants of financial performance in the event that teams are used, and the unobserved determinants of teams are assumed uncorrelated with the unobserved determinants of autonomy, of financial performance in the event that teams are used, and of financial performance in the event that teams are not used. The issue is not discussed in the literature, because in single-equation models with only one disturbance specified, all of these restrictions are implicit rather than explicit as they are in my model. My approach treats $\sigma_{02}, \sigma_{12}, \sigma_{13}$, and $\sigma_{23}$ as unrestricted parameters to be estimated.

\section{ESTIMATION RESULTS FROM STRUCTURAL MODEL}

Table 5 displays means and standard deviations of the variables in the model, and Table 6 displays the parameter estimates. ${ }^{13}$ Of greatest interest in this study are the magnitudes of the treatment effects of teams and autonomy on financial performance, and these cannot be discerned directly from Table 6 . The treatment effects of interest are functions of all of the parameters in Table 6. I define these functions in the following subsections, but before doing so it is worth commenting on the estimated values of the disturbance covariances and on the signs of some parameters of interest in the teams and autonomy equations.

Recall that $\sigma_{02}$ denotes the covariance of unobserved determinants of teams with unobserved determinants of financial performance given that teams are not used, $\sigma_{12}$ denotes the covariance of unobserved determinants of teams with unobserved determinants of financial performance given that teams are used, $\sigma_{23}$ denotes the covariance of unobserved determinants of teams with unobserved determinants of autonomy given that teams are used, and $\sigma_{13}$ denotes the covariance of unobserved determinants of autonomy given that teams are used with unobserved determinants of financial performance given that teams are used. The estimates of these covariance parameters are as follows: $\sigma_{02}=0.69, \sigma_{12}=0.27, \sigma_{13}=-0.73$, and $\sigma_{23}=-0.13$. The estimates of $\sigma_{02}$ and $\sigma_{13}$ are large in magnitude and statistically significant. The finding that $\sigma_{02}$ and $\sigma_{12}$ are positive means that unobserved factors that influence the use of teams influence 
financial performance in the same direction, so that the factors that make an establishment likely to engage in teams are also likely to make that establishment a high performer. An example of such an omitted factor would be the degree of supervisory skill, which might be particularly important in determining financial performance in the absence of teams when there is no group to eliminate or subsume some of the supervisory functions.

The result that $\sigma_{13}$ is negative might lead us to expect that establishments with autonomous teams tend to have lower financial performance than those with non-autonomous teams. The result means that the unobserved factors making autonomy more likely when teams are used tend to lower financial performance when teams are used. One example of such an unobserved factor might be the presence of fun, likable, and laid back managers at the workplace. While such managers might be beloved by team members and more likely to grant autonomy to teams, these attributes might suggest inattentiveness to the bottom line. Another example of such a factor is the extent to which the production process is such that workers are better able to acquire productivity-enhancing private information than are managers. Consistent with the discussion in Aghion and Tirole (1997), the firm in such situations is more likely to delegate authority to the teams so as to give team members an incentive to invest in acquiring the information. But financial performance is likely to be lower in such situations than it would be if managers rather than team members were better able to acquire the productivity-enhancing information, since the interests of managers are more closely aligned with those of shareholders than are the interests of workers in teams, thereby allowing managers to retain control and use the information to maximum benefit for the firm. An alternative and closely related possibility, consistent with the informational rationale for delegation of authority as discussed in Dessein (2002), is that workplaces vary in the extent to which workers already possess private information that could enhance productivity. To the extent that the firm cannot verify the claims of the better-informed team members, it is better off delegating decision rights to the team (making the team more likely to use all of this private information when making decisions regarding production) than relying on the information that can be induced from team members' claims. However, financial performance is likely to be lower in these situations than it would be in workplaces where most of the productivity-enhancing private information was held by managers, since then the firm would have the option of using the information without relinquishing control to team members.

Other parameters of interest are the coefficients on "just-in-time" in the TEAMS equation, and those on the four variables unique to the autonomy equation. All of these parameters have the expected signs. That is, just-in-time is associated with a greater propensity 
to engage in team production, and autonomy is more likely to be granted to teams when 1) managers disagree with the statement that those at the top are best placed to make decisions about the workplace, 2) managers disagree with the statement that most decisions at the workplace are made without employee consultation, 3) managers report that employees at the workplace are fully committed to the values of the organization, and 4) a large fraction of employees at the establishment sometimes work at home during normal business hours.

\section{Effect of Team Production on Financial Performance}

Let us first consider the overall effect of teams on financial performance, leaving aside for now the issue of whether such teams are autonomous. The effect of teams on financial performance is measured as the change in the probabilities that financial performance is in each of three categories when team production is used in the largest occupational group compared to when it is not used. That is, the following three measures give the effect of team production on financial performance for establishment $\mathrm{i}^{14}$

$(\text { Effect A1 })_{\mathrm{i}}=\operatorname{Prob}\left(\right.$ FINPER $_{\mathrm{i}}=1 \mid$ TEAMS $\left._{\mathrm{i}}=1\right)-\operatorname{Prob}\left(\right.$ FINPER $_{\mathrm{i}}=1 \mid$ TEAMS $\left._{\mathrm{i}}=0\right)$

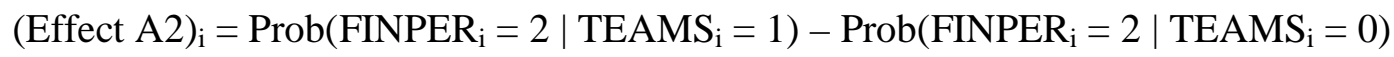

$(\text { Effect A3 })_{\mathrm{i}}=\operatorname{Prob}\left(\right.$ FINPER $_{\mathrm{i}}=3 \mid$ TEAMS $\left._{\mathrm{i}}=1\right)-\operatorname{Prob}\left(\right.$ FINPER $_{\mathrm{i}}=3 \mid$ TEAMS $\left._{\mathrm{i}}=0\right)$

Recall that FINPER reflects self-reports by the respondent manager concerning the establishment's current financial performance (interpreted as profit or value added) relative to that of others in the same industry, where $1=$ at or below the industry average, $2=$ above the industry average, and $3=$ a lot above the industry average.

Since for an individual establishment these three effects must sum to zero, any two of them contain all of the relevant information about the effect of team production on that establishment's financial performance. Figure 1 plots an ordered pair, (Effect A1, Effect A3), for each workplace, providing a visual description of the predicted effects of team production on financial performance. Establishments predicted to benefit the most from team production are those farthest from the origin in the second quadrant, and those predicted to be hurt the most are farthest from the origin in the fourth quadrant. Only a small number of establishments clustered about the origin fall into either of the other quadrants. While the predicted effect of team production is positive for many establishments and negative for many others, the positive effects appear to dominate. There are some cases of extreme effects, most notably the outlying 
workplace in the fourth quadrant with the most detrimental predicted effect of team production. For this reason I prefer the median effect to the mean when describing the "typical" workplace.

The scatter plot reveals the predicted effects but says nothing about how precisely they are estimated. To conduct statistical inference, I first construct a univariate measure of the effect of team production on financial performance, and I rank the establishments by this measure. Since large values of Effect A3 and small values of Effect A1 imply larger positive predicted effects of teams, the difference (Effect A3 - Effect A1) is a natural measure. ${ }^{15}$ Establishments far in the northwest corner of Figure 1 will rank the highest by this measure, and those far in the southeast corner will rank the lowest. Given an ordered ranking of establishments by their values of (Effect A3 - Effect A1), I select three establishments of interest (the median establishment; the establishment at the $25^{\text {th }}$ percentile; and the establishment at the $75^{\text {th }}$ percentile) and determine whether their respective values of Effects A1, A2, and A3 are statistically significantly different from zero. The rationale for considering the two quantiles other than the median is to get a sense of the magnitude of predicted benefits of team production for an establishment that has a higher predicted benefit than most and one that has a lower predicted benefit than most. These comparisons are interesting given the wide range of predicted benefits of team production displayed in Figure 1. ${ }^{16}$

\section{Effect of Autonomous and Non-Autonomous Team Production on Financial Performance}

For the same three workplaces, I next ask how they are predicted to benefit from autonomous team production versus non-autonomous team production. Again, there are three relevant measures describing autonomous team production and another three for nonautonomous team production, analogous to Effect A1, A2, and A3 for teams in general. ${ }^{17}$

What is the effect of autonomous, or self-managing, teams on financial performance?

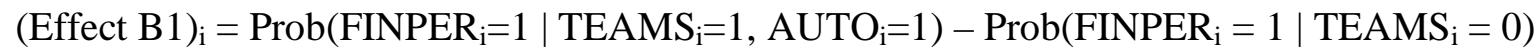

$\left(\right.$ Effect B2 $_{\mathrm{i}}=\operatorname{Prob}\left(\right.$ FINPER $_{\mathrm{i}}=2 \mid$ TEAMS $_{\mathrm{i}}=1$, AUTO $\left._{\mathrm{i}}=1\right)-\operatorname{Prob}\left(\right.$ FINPER $_{\mathrm{i}}=2 \mid$ TEAMS $\left._{\mathrm{i}}=0\right)$

$\left(\right.$ Effect B3 $_{\mathrm{i}}=\operatorname{Prob}\left(\right.$ FINPER $_{\mathrm{i}}=3 \mid$ TEAMS $_{\mathrm{i}}=1$, AUTO $\left._{\mathrm{i}}=1\right)-\operatorname{Prob}\left(\right.$ FINPER $_{\mathrm{i}}=3 \mid$ TEAMS $\left._{\mathrm{i}}=0\right)$

What is the effect of non-autonomous, or closely-managed, teams on financial performance? $(\text { Effect C1 })_{\mathrm{i}}=\operatorname{Prob}\left(\right.$ FINPER $_{\mathrm{i}}=1 \mid$ TEAMS $_{\mathrm{i}}=1$, AUTO $\left._{\mathrm{i}}=0\right)-\operatorname{Prob}\left(\right.$ FINPER $_{\mathrm{i}}=1 \mid$ TEAMS $\left._{\mathrm{i}}=0\right)$ 
$(\text { Effect C2 })_{\mathrm{i}}=\operatorname{Prob}\left(\right.$ FINPER $_{\mathrm{i}}=2 \mid$ TEAMS $_{\mathrm{i}}=1$, AUTO $\left._{\mathrm{i}}=0\right)-\operatorname{Prob}\left(\right.$ FINPER $_{\mathrm{i}}=2 \mid$ TEAMS $\left._{\mathrm{i}}=0\right)$

$(\text { Effect C3 })_{\mathrm{i}}=\operatorname{Prob}\left(\right.$ FINPER $_{\mathrm{i}}=3 \mid$ TEAMS $_{\mathrm{i}}=1$, AUTO $\left._{\mathrm{i}}=0\right)-\operatorname{Prob}\left(\right.$ FINPER $_{\mathrm{i}}=3 \mid$ TEAMS $\left._{\mathrm{i}}=0\right)$

A convenient way to assess the incremental effect of autonomy on financial performance, given that teams are used, is to consider the difference between the "B Effects" and the " $\mathrm{C}$ Effects", as follows:

$(\text { Effect D1 })_{\mathrm{i}}=(\text { Effect B1 })_{\mathrm{i}}-(\text { Effect } \mathrm{C} 1)_{\mathrm{i}}=$ $\operatorname{Prob}\left(\right.$ FINPER $_{\mathrm{i}}=1 \mid$ TEAMS $_{\mathrm{i}}=1$, AUTO $\left._{\mathrm{i}}=1\right)-\operatorname{Prob}\left(\right.$ FINPER $_{\mathrm{i}}=1 \mid$ TEAMS $_{\mathrm{i}}=1$, AUTO $\left.=0\right)$

$(\text { Effect D2 })_{\mathrm{i}}=(\text { Effect B2 })_{\mathrm{i}}-(\text { Effect C2 })_{\mathrm{i}}=$ $\operatorname{Prob}\left(\right.$ FINPER $_{\mathrm{i}}=2 \mid$ TEAMS $_{\mathrm{i}}=1$, AUTO $\left._{\mathrm{i}}=1\right)-\operatorname{Prob}\left(\right.$ FINPER $_{\mathrm{i}}=2 \mid \mathrm{TEAMS}_{\mathrm{i}}=1$, AUTO $\left.=0\right)$

$(\text { Effect D3 })_{i}=(\text { Effect B3 })_{i}-(\text { Effect C3 })_{i}=$ $\operatorname{Prob}\left(\right.$ FINPER $_{\mathrm{i}}=3 \mid$ TEAMS $_{\mathrm{i}}=1$, AUTO $\left._{\mathrm{i}}=1\right)-\operatorname{Prob}\left(\right.$ FINPER $_{\mathrm{i}}=3 \mid$ TEAMS $_{\mathrm{i}}=1$, AUTO $\left.=0\right)$

I compute the B, C, and D effects for the same three workplaces previously selected.

Table 7 displays the key results of this study. Results for the workplace at the $25^{\text {th }}$ percentile of (Effect A3 - Effect A1) are in the top panel, those for the workplace at the median are in the middle panel, and those for the workplace at the $75^{\text {th }}$ percentile are in the lower panel. In each panel, the first column reports Effects A1, A2, and A3, the second column reports Effects B1, B2, and B3, the third column reports Effects C1, C2, and C3, and the fourth column reports Effects D1, D2, and D3. Given the definition of the "D" effects, the fourth column is simply the second column less the third.

As seen in the first column, the predicted benefit of team production for the median establishment is considerable, with an 8.7 percentage point increase in the probability that financial performance is a lot better than the industry average. The fact that the effect of teams on financial performance is positive is consistent with our earlier observation that $\sigma_{02}$ and $\sigma_{12}$ are positive. As is clear from the remaining columns of Table 7, and foreshadowed by our earlier observation that $\sigma_{13}$ is negative, the hypothesis that the predicted benefits from autonomous team production exceed those from non-autonomous production is clearly rejected by the data since the point estimates suggest just the opposite. As shown in the fourth column, while the point 
estimates reveal that the predicted benefit of team production is actually reduced by autonomy for the median establishment, the null hypothesis of no difference between autonomous and nonautonomous teams cannot be rejected at conventional levels. ${ }^{18}$ The finding that non-autonomous teams are no worse than autonomous ones for the typical establishment is interesting, given that much of the teams literature suggests that autonomous teams will more often be better than nonautonomous ones.

For the establishment at the 0.25 quantile of Effect A3 - Effect A1 (the predicted benefits of teams to financial performance), the predicted effect of team production on financial performance is negative but modest. Its magnitude is roughly half that for the median workplace. The comparison of autonomous to non-autonomous teams yields the same qualitative predictions as for the median workplace, though again the effect magnitudes are about half as large. For the establishment at the 0.75 quantile there is a large (more than twice the magnitude of the effect for the median workplace) and positive predicted effect of team production. The comparison of autonomous to non-autonomous teams yields the same qualitative predictions as at the other two quantiles, again with the magnitude of the effects more than twice the analogous effects for the median workplace. These results suggest that team production provides greater benefits to establishments it helps than costs to those it hurts, or that the "upside" from team production is greater than the "downside." However, there is a large variance in impacts, meaning that there is some risk to employers in adopting teams unless they have knowledge of where they are likely to locate in the distribution.

\section{Sensitivity Analysis ${ }^{19}$}

Though the WERS includes inverse-probability sampling weights, the results reported in this paper are based on unweighted estimation, since convergence proved more difficult to obtain in the presence of sampling weights and the computation of standard errors required estimated the model a large number of times. It is therefore crucial to establish that any non-randomness introduced by ignoring the sampling weights does not have implications for the treatment effects of interest. The effects of teams and autonomy on financial performance appear to be quite invariant to the incorporation of sampling weights into the analysis. For example, a simple regression of financial performance on teams for the same estimation sample that generated Table 7 yields results that differ only in the third decimal place between the weighted and 
unweighted sample (the teams coefficient is 0.111 without weights and 0.113 with weights). Similar small differences between weighted and unweighted results are found when controls for industry, establishment size, and other firm characteristics are included in the model and when considering differences between autonomous and non-autonomous teams. I also estimated several specifications of the structural model using weighted maximum likelihood, relying on the smaller sets of control variables for which convergence was readily achieved, and compared the results to the identical unweighted specifications. Across all of these comparisons I found that the "Table 7 effects" of interest were similar between the weighted and unweighted estimations. It appears reasonable to conclude that any non-randomness introduced by relying on unweighted estimation has no material impact on the treatment effects of interest.

The results I report in this study are based on the specification of exogenous variables detailed in the Appendix. I also estimated several alternative versions of the model to gauge the robustness of the results to changes in the specification. In general, the effects of interest in this model are quite stable across specifications. For example, an earlier version of the paper that omitted the additional control variables recommended by the referees from the financial performance equation (namely Financial Participation, Owner Manager, Foreign Owned, Operation Over Five Years, Number of Recognized Unions, Multi-Skilling, Induction Training, and Off-Site Training) yielded virtually the same results, both qualitatively and in magnitudes, as those presented in the present version. I also tried including these additional controls in the teams and autonomy equations as well, and the results of interest change little.

Probably the most important alternative specification concerns occupation and industry controls. I included these in both the teams and autonomy equations. Industry controls are statistically insignificant in the financial performance equation since the survey asks the employer to rate the establishment's current financial performance compared with that of other establishments in the same industry, so industry differences in financial performance are in effect already accounted for by the nature of the question. Since both the team and autonomy variables are defined in terms of the establishment's largest occupational group, I estimated specifications that included in both of these equations a set of occupational dummy variables indicating the establishment's largest occupational group. Although I report only the results from a model that omits industry and occupation controls, the results from the more general specification that 
includes these controls are similar both qualitatively and quantitatively in terms of the effects of interest. $^{20}$

To assess whether the main results are sensitive to the definition of team autonomy, I also estimated the model using the two alternative measures that capture different dimensions of team autonomy. I then recomputed the key table of interest using the estimates from these alternative models, reporting the results in Tables 8 and 9. The conclusions that emerge are qualitatively similar to those of the main results in Table 7. That is, team production has a positive effect on financial performance for the median workplace, autonomous teams and non-autonomous teams are equally (in a statistical sense) beneficial in terms of their effects on financial performance, and the positive effect of teams for the workplace at the $75^{\text {th }}$ percentile is far larger in magnitude than the negative effect of teams for the workplace at the $25^{\text {th }}$ percentile.

I also estimated the model on the full sample rather than focusing only on observations for which the financial performance measure was interpreted to mean profit or value added. ${ }^{21}$ If one is prepared to take the implications of perfect competition and profit maximization to their extremes, then profitability should be telling us roughly the same thing as costs or productivity and possibly even share price. Nonetheless, I am uncomfortable pooling interpretations that are known to be different. For the record, Table 10 displays the effects of interest, which differ substantially from those in Table 7 in that they imply an extremely small (and statistically insignificant) positive effect of teams for the median workplace. For example, (Effect A3 Effect A1) is only 0.052 in the full-sample as opposed to 0.176 in the "profit" subsample. I interpret this large discrepancy as confirmatory evidence that the various interpretations on the dependent variable are measuring different things and should not be pooled. ${ }^{22}$

I also consider the sensitivity of the results to the definition of the binary teams variable indicating whether any employees in the largest occupational group at the workplace are organized in formally designated teams, by estimating a model using a TEAMS dummy defined to be one if the fraction of workers in the largest occupational group that are in formally designated teams is less than $20 \%$ and zero otherwise. While the results are qualitatively similar to the main results in this paper, they are smaller in magnitude. That is, the effects of teams on the probabilities that financial performance is at or below the industry average or a lot above the industry average for the median workplace are -0.066 and 0.047 , as opposed to -0.089 and 0.087 from Table 7. As in the main results, the point estimates suggest a slightly larger benefit from 
non-autonomous teams than from autonomous teams, though again the difference is not statistically significant.

I also estimated the model eliminating all observations pertaining to public sector establishments since these may be very different from private sector ones. I found no noteworthy difference in the results. As a final sensitivity check, I tried relaxing the implicit restriction that the threshold parameter, $\mathrm{c}$, is the same in both equations for the financial performance index. Distinct threshold parameters are, in principle, identified for each financial performance equation. Since the qualitative results that emerge from relaxing this assumption are similar to those in the paper, and since a likelihood ratio test fails to reject the restriction, I report only the results based on a common threshold parameter.

\section{Results from A Non-Structural Approach}

A frequent approach in the empirical teams literature and in strategic management research more generally is to treat choice variables of the firm (such as teams and autonomy) as exogenous variables on the right-hand side of regressions of organizational outcomes, despite potential correlations between unobservable determinants of choices and outcomes. Only a small minority of studies in a prominent strategic management journal account for such endogeneity (Hamilton and Nickerson 2003). It is therefore interesting to ask how the results would have differed if we had ignored these endogeneity issues in the analysis. In the present context, treating teams and autonomy as exogenous amounts to assuming uncorrelated disturbances across equations, so that $\Sigma=\mathbf{I}$. This amounts to estimating the model equation by equation, treating the financial performance equation as a switching model with exogenous switching and an exogenous autonomy regressor. A likelihood ratio test rejects these “exogeneity" restrictions at the five percent level, with a p-value of 0.04. Table 11 displays estimates from this restricted model.

In Table 12 we see that the effects of interest differ from those in the structural results of Table 7, with somewhat less favorable results for teams overall and an improvement of autonomous teams relative to non-autonomous teams especially at the 0.75 quantile. While qualitatively the two sets of results are similar, there are some noteworthy differences in magnitudes. For example, the structural results suggest that for the median workplace the use of team production implies an increase of 8.7 percentage points in the probability that financial 
performance is a lot better than the industry average. Using the nonstructural estimates that ignore the endogeneity of teams and autonomy, the corresponding effect is half as large.

The signs and magnitudes of the four free cross-equation disturbance covariances determine the nature of the two types of biases introduced by ignoring the endogeneity of teams and autonomy (i.e. underestimating the benefits of teams overall and overestimating the benefits of autonomous teams relative to non-autonomous teams). In particular, these results are driven by the two covariance parameters that are large in magnitude and statistically significant in Table 6 , namely $\sigma_{02}$ (the correlation between unobserved determinants of teams and of financial performance given that teams are not chosen) and $\sigma_{13}$ (the correlation between unobserved determinants of financial performance given that teams are chosen and of autonomy given that teams are chosen). This can be understood by considering how the two functions (Effect A3 Effect A1) and (Effect D3 - Effect D1) vary as functions of the covariance parameters in the neighborhood of the constrained optimum in which the four disturbance covariances are constrained to be zero, when all other parameters are held constant. The first of these functions, (Effect A3 - Effect A1), is a measure of the degree to which all teams benefit financial performance. The second of these functions, (Effect D3 - Effect D1), is a measure of the benefits of autonomous teams relative to those of non-autonomous teams, so that positive values of this function indicate that autonomous teams yield greater benefits to financial performance and negative values indicate that non-autonomous teams yield greater benefits. In the neighborhood of the constrained optimum, the function (Effect A3 - Effect A1) is increasing in $\sigma_{02}$, the correlation between unobserved determinants of teams and of financial performance given that teams are not chosen. Hence, in the unconstrained structural model in which this parameter is allowed to increase to a large positive value, the overall benefit of teams to financial performance also becomes greater. Also in the neighborhood of the constrained optimum, the function (Effect D3 - Effect D1) is decreasing in $\sigma_{13}$, the correlation between unobserved determinants of financial performance given that teams are chosen and of autonomy given that teams are chosen. Hence, in the unconstrained model in which this parameter is allowed to decrease to a negative value that is large in magnitude, the benefits to financial performance of autonomous teams relative to non-autonomous teams diminish. 


\section{CONCLUDING REMARKS}

The results of this study confirm the popular belief in management circles that team production is a good bet for enhancing organizational performance. The median establishment in a large cross section enjoys a considerable increase in the probability of higher financial performance by using team production, and the benefits are considerably larger for establishments at higher quantiles. Furthermore, even at low quantiles of the team effect, statistical evidence of a detrimental effect of teams on financial performance is quite weak. This suggests that the upside from team production is much larger than the downside.

Contrary to the commonly held belief in the management and academic communities that self-managed or autonomous teams are preferable to closely-managed teams, the evidence suggests that non-autonomous teams are no worse, regardless of the autonomy measure considered. In fact, while the median workplace benefits from using non-autonomous teams, the corresponding effect for autonomous teams is statistically insignificant and half as large as the non-autonomous teams effect. At higher quantiles there are significant positive effects of selfmanaged teams on financial performance, but the same is true for non-autonomous teams for which the point estimates are even larger. The results should not be interpreted as evidence that autonomous team production is worse than non-autonomous team production, but rather that it is clearly no better. Although the point estimates suggest larger positive effects of non-autonomous teams than autonomous teams at each of the quantiles investigated, these differences between the two types of team production were statistically insignificant.

The results from this cross sectional study highlight the dangers of making a case for teams in general or for self-managed teams on the basis of samples drawn from narrowly defined populations such as single firms or particular types of firms in narrowly defined sectors. The estimated treatment effects of team production reveal a great diversity of possible effects of teams in the cross section, ranging from large negative to large positive effects. It is not surprising that the previous empirical literature has been mixed; depending on the production context teams can be beneficial, detrimental, or neutral. Although it should be expected that teams, self-managed or otherwise, will have positive effects in some case studies and negative or no effects in others, the evidence here suggests that the best description of the typical or median workplace is one in which team production has a positive effect, with autonomy doing nothing to enhance the positive effect on financial performance. 
Although this paper provides evidence that the median establishment benefits from team production, it does not illuminate the channels through which these benefits are realized. There are a number of theoretical channels through which team production could improve financial performance, including increased labor productivity or higher quality products and services. Surely the particular means through which team production provides benefits to the organization vary across production processes. To clarify the channel through which team production benefits the typical establishment, a promising direction for future work in the spirit of this paper would be to investigate in large cross sections the intermediate stages between the black box of organizational structure and the end result of profit. 


\section{APPENDIX}

\section{Exogenous Variables Included in the Model}

I included the following common set of control variables in each of $\mathbf{X}_{1}, \mathbf{X}_{2}$, and $\mathbf{X}_{3}$.

Single-Establishment Firm: dummy variable that equals 1 if the establishment is either a single independent establishment not belonging to another body, or the sole UK establishment of a foreign organization and equals 0 if the establishment is one of a number of different establishments within a larger organization

Establishment Size: total number of full time, part time, and temporary workers at the establishment

Fraction of Part Time Workers: number of part time workers at the establishment as a fraction of establishment size

Temporary Workers: dummy variable that equals 1 if there are temporary agency employees working at the establishment at the time of the survey and equals 0 otherwise

Fixed Term Workers Under One Year: dummy variable that equals 1 if there are employees who are working on a temporary basis or have fixed-term contracts for less than one year and equals 0 otherwise

Fixed Term Workers Over One Year: dummy variable that equals 1 if there are employees who have fixed term contracts for one year or more and equals 0 otherwise

Union workers: dummy variables that equals 1 if any of the workers at the establishment belong to a union and equals 0 otherwise

Private Sector Franchise: dummy variable that equals 1 if the establishment is a private sector company and a franchise and equals 0 otherwise

Private Sector Non-franchise: dummy variable that equals 1 if the establishment is a private sector company but not a franchise and equals 0 otherwise

Alternative Private Sector Franchise: dummy variable that equals 1 if the establishment is an alternative private sector firm and a franchise and equals 0 otherwise

Alternative Private Sector Non-franchise: dummy variable that equals 1 if the establishment is an alternative private sector firm but not a franchise and equals 0 otherwise

On the suggestions of the referees, I included the following additional control variables in the financial performance equation. A number of these have been found to be significantly associated with financial performance in previous analyses of the WIRS/WERS data, for 
example, union activity, (Bryson and Wilkinson, 2002); training (Collier et al, 2003); and financial participation (McNabb and Whitfield, 1998).

Financial Participation: dummy variable that equals 1 if any employees at the workplace receive payments or dividends from any of the following variable pay schemes (profitrelated payments or bonuses, deferred profit sharing schemes, employee share ownership schemes, individual or group performance-related schemes, other cash bonus). This variable was included in the financial performance equation in $\mathrm{McNabb}$ and Whitfield 1998 and found to be significant; their study used data from an earlier wave of the survey, so their definition of this variable differed slightly from ours.

Owner Manager: dummy variable that equals one if any of the controlling owners of the workplace are actively involved in day-to-day management on a full-time basis, and zero otherwise. This question was only asked of private sector workplaces for which a single individual or family has controlling interest (meaning at least $50 \%$ ownership) over the company.

Foreign Owned: dummy variable that equals one if workplace reports that either of the following two statements best describes the ownership of the workplace (predominantly foreign owned, meaning 51\% or more; foreign owned/controlled) and zero if any of the following three statements is chosen (UK owned/controlled, predominantly UK owned, meaning $51 \%$ or more; UK and foreign owned). This question was asked only of private sector workplaces.

Operation Over Five Years: dummy variable that equals one if the workplace has been operating at its present address for 5 years or more, and zero otherwise

Multi-Skilling: Degree of multi-skilling at the workplace in the largest occupational group. Question asks what fraction of these employees are formally trained to be able to do jobs other than their own. Responses are: "None 0\%" (1); "Just a few 1-19\%" (2); "Some 2039\%" (3); "Around half 40-59\%" (4); "Most 60-79\%" (5); "Almost all 80-99\%" (6); "All $100 \% "(7)$.

Number of Recognized Unions: Total number of recognized unions at the workplace

Induction Training: dummy variable that equals one if there is a standard induction programme designed to introduce new employees (in the largest occupational group) to the workplace, and zero otherwise.

Off-site Training: discrete variable measuring the proportion of experienced employees (in the largest occupational group) that have had formal off-the-job training (away from the normal place of work, but either on or off the premises) over the last 12 months. Responses are: "None 0\%" (1); "Just a few 1-19\%" (2); "Some 20-39\%" (3); "Around half 40-59\%" (4); "Most 60-79\%" (5); "Almost all 80-99\%" (6); "All 100\%" (7). 
In the TEAMS equation I include a dummy variable indicating whether a just-in-time system is in operation at the establishment. Specifically, the employer is asked "Does this workplace operate a system designed to minimize inventories, supplies or work-in progress? This is sometimes known as Just-in-Time.” Responses are coded as one for yes and zero for no.

In the autonomy equation I include a set of four proxies for the organizational and informational structure of the establishment, the alignment of incentives between workers and owners, and the importance to the firm of monitoring inputs. The first three of these are qualitative measures of managerial opinion. The respondent manager is asked to comment on each of a list of statements, responding with "Strongly agree" (1), "Agree" (2), "Neither agree nor disagree" (3), "Disagree" (4), or "Strongly disagree" (5). The questions of interest as determinants of team autonomy are as follows:

Information: "Those at the top are best placed to make decisions about this workplace." Incentive Alignment: "Employees here are fully committed to the values of this organization."

Decisions: "Most decisions at this workplace are made without consulting employees."

In addition to these managerial opinion variables, as a proxy for the importance the employer places on monitoring worker inputs, I include a discrete variable measuring the proportion of workers at the establishment that ever work from home during normal working hours. Responses include: "Half or more 50\%+", "A quarter up to a half 25-49\%", "Up to a quarter 1024\%", "A small proportion 5-9\%", "Hardly any (less than 5\%)", or "None 0\%".

The full specification of the exogenous variables in $\mathbf{X}_{\mathbf{1}}, \mathbf{X}_{\mathbf{2}}$, and $\mathbf{X}_{\mathbf{3}}$ is summarized in the following table. 
Exogenous Variables Included in Structural Model

\begin{tabular}{|c|c|c|c|}
\hline & FINPER $_{i}$ & $T E A M S_{i}$ & $\mathrm{AUTO}_{i}$ \\
\hline & $\mathbf{X}_{1}$ & $\mathbf{X}_{2}$ & $\mathbf{X}_{3}$ \\
\hline Single-Establishment Firm & YES & YES & YES \\
\hline Establishment Size & YES & YES & YES \\
\hline Fraction of Part Time Workers & YES & YES & YES \\
\hline Temporary Workers & YES & YES & YES \\
\hline Fixed Term Workers Under One Year & YES & YES & YES \\
\hline Fixed Term Workers Over One Year & YES & YES & YES \\
\hline Union Workers & YES & YES & YES \\
\hline Private Sector Franchise & YES & YES & YES \\
\hline Private Sector Non-franchise & YES & YES & YES \\
\hline Alternative Private Sector Franchise & YES & YES & YES \\
\hline Alternative Private Sector Non-franchise & YES & YES & YES \\
\hline Financial Participation & YES & & \\
\hline Owner Manager & YES & & \\
\hline Foreign Owned & YES & & \\
\hline Operation Over Five Years & YES & & \\
\hline Multi-Skilling (1-5) & YES & & \\
\hline Number of Recognized Unions & YES & & \\
\hline Induction Training & YES & & \\
\hline Off-site Training & YES & & \\
\hline Just-In-Time Production & & YES & \\
\hline Information & & & YES \\
\hline Incentive Alignment & & & YES \\
\hline Decisions & & & YES \\
\hline Work at Home & & & YES \\
\hline
\end{tabular}




\section{Constructing the Likelihood Function}

The statistical model can be described as a simultaneous system involving both a censored probit and an ordered probit switching model with endogenous switching. Note that for the $\mathrm{i}^{\text {th }}$ workplace in the data there are nine possible discrete outcomes. Letting $\boldsymbol{\theta}$ denote the vector of parameters in the model, the probabilities of these outcomes and the corresponding values of the discrete endogenous variables in the model are as follows:

\begin{tabular}{||l|c|c|c||}
\hline \hline Probability & FINPER $_{i}=$ & TEAMS $_{i}=$ & AUTO $_{i}=$ \\
\hline $\mathrm{P}_{1 \mathrm{i}}(\boldsymbol{\theta})$ & 1 & 1 & 1 \\
\hline $\mathrm{P}_{\mathrm{i}}(\boldsymbol{\theta})$ & 1 & 1 & 0 \\
\hline $\mathrm{P}_{3 \mathrm{i}}(\boldsymbol{\theta})$ & 2 & 1 & 1 \\
\hline $\mathrm{P}_{4 \mathrm{i}}(\boldsymbol{\theta})$ & 2 & 1 & 0 \\
\hline $\mathrm{P}_{5 \mathrm{i}}(\boldsymbol{\theta})$ & 3 & 1 & 1 \\
\hline $\mathrm{P}_{6 \mathrm{i}}(\boldsymbol{\theta})$ & 3 & 1 & 0 \\
\hline $\mathrm{P}_{7 \mathrm{i}}(\boldsymbol{\theta})$ & 1 & 0 & unobserved \\
\hline $\mathrm{P}_{8 \mathrm{i}}(\boldsymbol{\theta})$ & 2 & 0 & unobserved \\
\hline $\mathrm{P}_{9 \mathrm{i}}(\boldsymbol{\theta})$ & 3 & 0 & unobserved \\
\hline
\end{tabular}

Let $\mathrm{Z}_{\mathrm{ji}}=1$ if workplace $\mathrm{i}$ experiences the $\mathrm{j}^{\text {th }}$ outcome

$=0$ otherwise, for $\mathrm{i}=1,2, \ldots, \mathrm{N}$ and $\mathrm{j}=1,2, \ldots, 9$

Then the likelihood function, $\mathrm{L}^{*}$, is

$L^{*}=\prod_{i=1}^{N} \prod_{j=1}^{9} P_{j i}^{Z_{j i}} \quad$ and the log-likelihood function, $\mathrm{L}$, is

$L=\sum_{i=1}^{N} \sum_{j=1}^{9} Z_{j i} \log P_{j i}$

Since each of the endogenous variables is observed only discretely, each probability of the form $\mathrm{P}_{\mathrm{ji}}(\theta)$ is a multiple integral of the joint density $\mathrm{f}\left(\varepsilon_{0 \mathrm{i}}, \varepsilon_{1 \mathrm{i}}, \varepsilon_{2 \mathrm{i}}, \varepsilon_{3 \mathrm{i}}\right)$. Suppressing all subscripts $\mathrm{i}$, the expression for $\mathrm{P}_{1 \mathrm{i}}(\boldsymbol{\theta})$ is as follows:

$P_{1}(\theta)=\int_{-\infty}^{-\left(\alpha+X_{1} \delta_{1}\right)} \int_{-X_{2} \beta}^{\infty} \int_{-X_{3} \gamma}^{\infty} f\left(\boldsymbol{\varepsilon}_{1}, \mathcal{E}_{2}, \mathcal{E}_{3}\right) d \mathcal{E}_{3} d \mathcal{E}_{2} d \boldsymbol{E}_{1}$.

Probabilities $\mathrm{P}_{2}(\boldsymbol{\theta})$ to $\mathrm{P}_{9}(\boldsymbol{\theta})$ are similarly defined. 
I used the MAXLIK routine in GAUSS and the BFGS algorithm to maximize the loglikelihood function, using Gauss-Legendre quadrature to compute the multiple integrals that appear in the probability functions. Since a small number of establishments have missing values for some of the exogenous variables, the estimation sample sizes are slightly smaller than those listed in the tabulations of the endogenous variables in Table $4 .^{23}$ To produce starting values I estimated each equation individually using either probit or ordered probit estimation. Although only a subset of the parameters are consistently estimated using this method, the BFGS algorithm converged to a local maximum without incident. Given that part of the structural model is a switching model with endogenous switching, and that in such models it is not unusual for the log-likelihood function to have multiple local maxima (see, for example, Maddala and Nelson 1974), I also estimated the model from a variety of alternative starting vectors. In all cases in which convergence was achieved the same local maximum was always attained. I computed standard errors via the parametric bootstrap with 100 replications, using the following algorithm.

1. Take $\mathrm{N}$ pseudo-random draws from the standard normal distribution to simulate $\varepsilon_{2}$.

2. Compute TEAMS ${ }^{*}$ for each observation using the estimated parameters and the simulated disturbances from Step 1. Then use TEAMS* to compute TEAMS.

3. For all observations for which TEAMS $=0$ from Step 2, take a pseudo-random draw from the conditional distribution of $\varepsilon_{0}$ given $\varepsilon_{2}$ and use it in conjunction with the estimated parameters to compute FINPER ${ }^{*}$ and FINPER given that TEAMS $=0$.

4. For all observations for which TEAMS $=1$ from Step 2, take a pseudo-random draw from the conditional distribution of $\varepsilon_{3}$ given $\varepsilon_{2}$ and compute AUTO* and AUTO for these observations.

Next take a pseudo-random draw from the conditional distribution of $\varepsilon_{1}$ given $\varepsilon_{2}$ and $\varepsilon_{3}$ and use it in conjunction with AUTO and the estimated parameters to compute FINPER ${ }^{*}$ and FINPER given that TEAMS $=1$.

5. Combine the constructed variables FINPER, TEAMS, and AUTO with the actual exogenous variables $\mathbf{X}_{1}, \mathbf{X}_{2}$, and $\mathbf{X}_{3}$, to produce a bootstrap sample with which to estimate the model.

6. Estimate the model using the data from Step 5.

7. Repeat the above steps 100 times, and take the standard deviation of the sampling distribution for each parameter.

Treatment Effects of Interest for Teams and Autonomy 
The nine effects of interest are functions of the $\mathrm{P}_{\mathrm{j}}(\boldsymbol{\theta})$ and are computed as follows, evaluating the expressions for $\mathrm{P}_{\mathrm{j}}$ at the estimated values of $\boldsymbol{\theta}$ :

$(\text { Effect A1 })_{i}=\frac{P_{1 i}+P_{2 i}}{\sum_{j=1}^{6} P_{j i}} \frac{P_{7 i}}{\sum_{j=7}^{9} P_{j i}}$

$(\text { Effect A2 })_{i}=\frac{P_{3 i}+P_{4 i}}{\sum_{j=1}^{6} P_{j i}}-\frac{P_{8 i}}{\sum_{j=7}^{9} P_{j i}}$

$(\text { Effect A3 })_{i}=\frac{P_{5 i}+P_{6 i}}{\sum_{j=1}^{6} P_{j i}}-\frac{P_{9 i}}{\sum_{j=7}^{9} P_{j i}}$

$(\text { Effect B } 1)_{i}=\frac{P_{1 i}}{P_{1 i}+P_{3 i}+P_{5 i}}-\frac{P_{7 i}}{P_{7 i}+P_{8 i}+P_{9 i}}$

$(\text { Effect B2 })_{i}=\frac{P_{3 i}}{P_{1 i}+P_{3 i}+P_{5 i}}-\frac{P_{8 i}}{P_{7 i}+P_{8 i}+P_{9 i}}$

$(\text { Effect B3 })_{i}=\frac{P_{5 i}}{P_{1 i}+P_{3 i}+P_{5 i}}-\frac{P_{9 i}}{P_{7 i}+P_{8 i}+P_{9 i}}$

$(\text { Effect C } 1)_{i}=\frac{P_{2 i}}{P_{2 i}+P_{4 i}+P_{6 i}}-\frac{P_{7 i}}{P_{7 i}+P_{8 i}+P_{9 i}}$

$(\text { Effect C2 })_{i}=\frac{P_{4 i}}{P_{2 i}+P_{4 i}+P_{6 i}}-\frac{P_{8 i}}{P_{7 i}+P_{8 i}+P_{9 i}}$

$(\text { Effect C3 })_{i}=\frac{P_{6 i}}{P_{2 i}+P_{4 i}+P_{6 i}}-\frac{P_{9 i}}{P_{7 i}+P_{8 i}+P_{9 i}}$

$(\text { Effect D } 1)_{i}=\frac{P_{1 i}}{P_{1 i}+P_{3 i}+P_{5 i}}-\frac{P_{2 i}}{P_{2 i}+P_{4 i}+P_{6 i}}$

$(\text { Effect D2 })_{i}=\frac{P_{3 i}}{P_{1 i}+P_{3 i}+P_{5 i}}-\frac{P_{4 i}}{P_{2 i}+P_{4 i}+P_{6 i}}$

$(\text { Effect D3 })_{i}=\frac{P_{5 i}}{P_{1 i}+P_{3 i}+P_{5 i}}-\frac{P_{6 i}}{P_{2 i}+P_{4 i}+P_{6 i}}$ 


\section{REFERENCES}

Aghion, Philippe and Jean Tirole. 1997. "Formal and Real Authority in Organizations." Journal of Political Economy 105 (February): 1-29.

Alchian, Armen A. and Harold Demsetz. 1972. "Production, Information Costs, and Economic Organization.” American Economic Review 62 (December): 777-95.

Barker, J.R. 1993. "Tightening the Iron Cage: Concertive Control in Self-Managing Teams." Administrative Science Quarterly 38: 408-437.

Baron, James N. and David M. Kreps. Strategic Human Resources: Frameworks for General Managers. New York: John Wiley \& Sons, Inc., 1999.

Batt, Rosemary. 1999. "Work Organization, Technology, and Performance in Customer Service and Sales." Industrial and Labor Relations Review 52 (July): 539-64.

Batt, Rosemary. 2004. "Who Benefits from Teams? Comparing Workers, Supervisors, and Managers.” Industrial Relations 43 (Special Issue, January): 183-212.

Batt, Rosemary. 2001. "The Economics of Teams Among Technicians.” British Journal of Industrial Relations 39 (March): 1-24.

Becker, G., and K. Murphy. 1992. "The Division of Labor, Coordination Costs, and Knowledge.” Quarterly Journal of Economics 107 (November): 1137-1160.

Berg, Peter, Eileen Appelbaum, Thomas Bailey, and Arne L. Kallenberg. 1996. "The Performance Effects of Modular Production in the Apparel Industry." Industrial Relations 35 (July): 356-373.

Bolton, Patrick, and Mathias Dewatripont. 1994. "The Firm as a Communication Network." Quarterly Journal of Economics 109 (November): 809-839.

Boning, Brent, Casey Ichniowski, and Kathryn Shaw. 2003. "Opportunity Counts: Teams and the Effectiveness of Production Incentives." Working Paper No. 8306. Cambridge, MA: National Bureau of Economic Research.

Bryson, A. and D.Wilkinson. 2002. Collective Bargaining and Workplace Performance: An Investigation using the Workplace Employee Relations Survey 1998. Department of Trade and Industry Employment Relations Research Series, No. 12.

Cohen, Susan, and Diane Bailey. 1997. "What Makes Teams Work: Group Effectiveness Research from the Shop Floor to the Executive Suite." Journal of Management 23 (May-June): 239-90.

Collier, William, Francis Green, John Peirson, and David Wilkinson. 2004. "Training and 
Establishment Survival.” Working paper. University of Kent at Canterbury.

Cully, M., S. Woodland, A. O'Reilly, and G. Dix. 1999. Britain at Work: As Depicted by the 1998 Workplace Employee Relations Survey. London: Routledge.

Dessein, Wouter. 2002. "Authority and Communication in Organizations." Review of Economic Studies 69 (October): 811-838.

DeVaro, Jed, Robert Li and Dana Samuelson. 2004. "Analyzing the Job Characteristics Model: New Support from a Cross Section of Firms.” Working paper. Cornell University.

DeVaro, Jed, and Fidan Ana Kurtulus. 2005. "What Types of Organizations Benefit from Team Production, and How Do They Benefit?" Forthcoming in Advances in the Economic Analysis of Participatory and Labor-Managed Firms, Volume 9.

Encinosa, William E., Martin Gaynor and James B. Rebitzer. 2000. "The Sociology of Groups and the Economics of Incentives: Theory and Evidence on Compensation Systems." Carnegie Mellon University. Mimeo.

Garicano, Luis. 2000. "Hierarchies and the Organization of Knowledge in Production." Journal of Political Economy 108 (October): 874-904.

Gaynor, Martin and Paul J. Gertler. 1995. "Moral Hazard and Risk Spreading in Medical Partnerships.” Rand Journal of Economics 26 (Winter): 591-613.

Grossman, Sanford J., and Oliver Hart. 1986. "The Costs and Benefits of Ownership: A Theory of Vertical and Lateral Integration.” Journal of Political Economy 94 (August): 691-719.

Hackman, J.R., and G.R. Oldham. 1976. "Motivation through the Design of Work: Test of a Theory." Organizational Behavior and Human Performance 16, 250-279.

Hackman, J.R., and G.R. Oldham. 1980. Work Design. Reading, MA: AddisonWesley.

Hackman, J.R. 1987. “The Design of Work Teams.” In Handbook of Organizational Behavior, edited by J. Lorsch. Englewood Cliffs, NJ: Prentice-Hall.

Hamilton, Barton H. and Jack A. Nickerson. 2003. "Correcting for Endogeneity in Strategic Management Research.” Strategic Organization 1: 53-80.

Hamilton, Barton H., Jack A. Nickerson, and Hideo Owan. 2003. “Team Incentives and Worker Heterogeneity: An Empirical Analysis of the Impact of Teams on Productivity and Participation.” Journal of Political Economy 111 (June), 465-97.

Hansen, Daniel. 1997. "Worker Performance and Group Incentives: A Case Study.” Industrial 
and Labor Relations Review 51 (October): 37-49.

Hart, Oliver. 1995. "Corporate Governance: Some Theory and Implications." The Economic Journal 105 (May): 678-89.

Hart, Oliver, and John Moore. 1990. "Property Rights and the Nature of the Firm." Journal of Political Economy 98 (December): 1119-58.

Ichniowski, C., K. Shaw., and G. Prennushi. 1997. "The Effects of Human Resource Management Practices on Productivity: A Study of Steel Finishing Lines." American Economic Review 87 (June): 291-313.

Holmstrom, Bengt. 1982. "Moral Hazard in Teams." Bell Journal of Economics 13 (Autumn): 324-40.

Itoh, Hideshi. 1991. "Incentives to Help in Multi-Agent Situations." Econometrica 59 (May): 611-636.

Itoh, Hideshi. 1992. "Cooperation in Hierarchical Organizations: An Incentive Perspective." Journal of Law, Economics, and Organization 8 (April): 321-345.

Jennergren, L. Peter. 1981. "Decentralization in Organizations." In Handbook of Organizational Design, vol. 2, Remodeling Organizations and Their Environments, edited by Paul C. Nystrom and William H. Starbuck. Oxford: Oxford University Press.

Kandel, Eugene, and Edward P. Lazear. 1992. "Peer Pressure and Partnerships.” Journal of Political Economy 100 (August): 801-17.

Lazear, Edward P. 1995. Personnel Economics. Cambridge, MA and London: MIT Press.

Lazear, Edward P. 1998. Personnel Economics for Managers. New York: John Wiley \& Sons, Inc.

Legros, Patrick, and Matthews, Steven A. 1993. "Efficient and Nearly Efficient Partnerships." Review of Economic Studies 60 (July): 599-611.

Leibowitz, Arleen and Robert Tollison. 1980. "Free Riding, Shirking and Team Production in Legal Partnerships.” Economic Inquiry 18 (July): 380-94.

Liberti, Jose Maria. 2003. "Initiative, Incentives, and Soft Information. How Does Delegation Impact the Role of Bank Relationship Managers?” Ph.D. diss. University of Chicago.

Machin, Stephen J., and Mark B. Stewart. 1996. "Trade Unions and Financial Performance." Oxford Economic Papers 48. 
Machin, Stephen J., and Mark B. Stewart. 1990. "Unions and the Financial Performance of British Private Sector Establishments." Journal of Applied Econometrics 5 (OctoberDecember): 327-50.

Maddala, G.S., and F. Nelson. 1974. "Maximum Likelihood Methods for Markets in Disequilibrium." Econometrica 42 (November): 1013-30.

McAfee, R. Preston, and McMillan, John. 1991. "Optimal Contracts for Teams.” International Economic Review 32 (August): 561-77.

McNabb, R. and K. Whitfield. 1997. "Unions, Flexibility, Team Working and Financial Performance." Organisation Studies, 18 (Winter): 821-38.

McNabb, R. and K. Whitfield. 1998. "The Impact of Financial Participation and Employee Involvement on Financial Performance." Scottish Journal of Political Economy 45 (May): 171-87.

Nalbantian, Haig R. and Andrew Schotter. 1997. "Productivity under Group Incentives: An Experimental Study.” American Economic Review 87 (June): 314-41.

Packard, David. 1996. The HP Way: How Bill Hewlett and I Built Our Company. HarperBusiness.

Pearce, J.A., and E.C. Ravlin. 1987. "The Design and Activation of Self-Regulating Work Groups.” Human Relations 40: 751-81.

Rasmusen, Eric. 1987. "Moral Hazard in Risk-Averse Teams." Rand Journal of Economics 18 (Autumn): 428-35.

Simon, Herbert A. 1951. "A Formal Theory of the Employment Relationship." Econometrica 19 (July): 293-305.

Stein, Jeremy. 2002. "Information Production and Capital Allocation: Decentralized versus Hierarchical Firms." The Journal of Finance 57 (October): 1891-1921.

Turner, A.N, and P.R. Lawrence. 1965. Individual Jobs and the Worker. Cambridge, MA: Harvard University Press.

Wall, T.D., J. Michie, M. Patterson, S. J. Wood, M. Sheehan, C. W. Clegg, and M. West. 2004. "On the validity of subjective measures of company performance". Personnel Psychology 57 (March): 95-118.

Workplace Employee Relations Survey: Cross-Section, 1998 [computer file]. 6th Edition. Department of Trade and Industry and Advisory, Conciliation and Arbitration Service. Colchester, Essex: UK Data Archive [distributor], January 2001. SN: 3955. 
${ }^{1}$ While concerns about free riding problems are frequent in economic discussions of teams, it is worth noting that the monitoring problems accompanying team production need not loom larger than those accompanying individual production. While traditional or direct monitoring methods are applied in cases of individual production, in the team context there is a greater tendency to rely on monitoring through peer pressure (Kandel and Lazear 1992). Which means of monitoring will be more effective obviously depends on the particular features of the production context. ${ }^{2}$ Hackman (1987) page 324. The autonomy condition is not the only one cited for a high level of team effort. Other conditions include the task requiring a variety of skills, that it is a whole and meaningful piece of work with a visible outcome, that it have significant consequences for other people, and that work on the task generates "regular, trustworthy feedback about how well the group is performing." These conditions parallel those for the job characteristics motivating individual workers as described in the Job Characteristics Model (Hackman and Oldham 1980).

${ }^{3}$ Aghion and Tirole (1997) offer the following slight modification of a passage from Simon (1951) that attempts to formally define worker authority. "We will say that [the boss] exercises authority over [the worker] if [the worker] permits [the boss] to select $\mathrm{x}$ [a 'behavior,' i.e., any element of the set of specific actions that the worker performs on the job]. That is, [the worker] accepts authority when his behavior is determined by [the boss's] decision. In general, [the worker] will accept authority only if $\mathrm{x}_{0}$, the $\mathrm{x}$ chosen by [the boss], is restricted to some given subset ([the worker's] 'area of acceptance') of all the possible values. This is the definition of authority that is most generally employed in modern administrative theory. See also Jennergren (1981)." This definition, focusing on a worker's degree of control over the "set of specific actions that the worker performs on the job" matches very closely my definition of autonomy (a team's control over how the work is to be done) in this paper. While the language in Aghion and Tirole concerns the delegation of authority at the level of the individual worker, the theory is as relevant in the team context as it is for individual workers.

${ }^{4}$ Rationales for team autonomy have also been offered outside of economics. One rationale, described nicely in Batt (1999), emerges from a body of work known as "socio-technical systems theory" (e.g. Pearce and Ravlin 1987) and argues that workers jointly optimize the social and technical systems of the organization, and when there is "fit" between these systems the "whole is greater than the sum of the parts." The socio-technical systems view is that autonomy produces benefits in three ways: first, by shifting the decision-making authority to workers who are closer to the production process and thereby most likely to possess the relevant information; second, by reaping performance gains that come from relying on internal group self-regulation as opposed to external monitoring; third, by eliminating or reducing the role of supervisors by shifting authority from top to bottom, implying greater responsibility for team members.

A second argument comes from the theory of motivational job design in a group context (Hackman 1987). This idea evolved from theory in organizational behavior on motivational job design for individual workers rather than teams (Hackman and Oldham 1976, 1980; Turner and Lawrence 1965). A recent review of the empirical literature on this model can be found in DeVaro, Li, and Samuelson (2004). According to the theory, the degree of autonomy a worker is granted affects three critical psychological states, which in turn induces a number of outcomes of interest both to workers and firms, such as high internal work motivation, high quality work performance, high satisfaction with work, and low absenteeism and turnover. Hackman (1987) applied these ideas to teams, synthesizing an extensive literature on group research to propose variables that are key to group job design. Hackman identified a number of task conditions that would produce high task motivation, and among these was autonomy. That is, the tasks assigned to the group should provide group members with substantial autonomy for deciding how best to accomplish them. This argument raises the question of what benefits team members derive from autonomy and whether they view autonomy as a "good" in and of itself or rather as a responsibility akin to management (and thereby deserving of financial rewards). That is, if some workers desire autonomy while others do not, the compensating differential arising from autonomy could be either positive or negative. These issues might be addressed empirically in future work by interacting measures of team autonomy with compensation.

${ }^{5}$ It is worth noting the limits of a purely economic approach to teams research. Political considerations as well as economic ones shape the formation and sustainability of teams. As argued in Batt (2004), if teams do not satisfy the self-interests of those workers responsible for their implementation, these workers have incentives to undermine and thwart the formation of teams. The Batt study shows how internal politics can reduce the likelihood of observing autonomous teams. In her study of 1200 workers, supervisors, and middle managers in a large unionized telecommunications company, even though top management and $70 \%$ of surveyed workers were in favor of selfmanaged teams, the plan was opposed and terminated early because of lack of support from supervisors and middle managers who experienced lower levels of decision-making discretion, security, and job satisfaction as the result of teams. 
${ }^{6}$ The responses sum to 1800 instead of the full 2191 because some respondents reported that no comparison was possible or that the relevant data were not available.

${ }^{7}$ The recent study by Wall et al. (2004) provides evidence supporting the validity of subjective measures of company performance using data from companies in the U.K. The authors present results from two studies, each of which compares subjective and objective measures of profit. The first study uses 80 U.K. manufacturing companies, a subjective profit measure of the form "What is your company's performance in comparison to your main competitors?" (with responses on a 5-point scale), and an objective measure of profit measured as the logarithm of the financial value of sales less costs. The second study uses a sample of 369 publicly quoted U.K. manufacturing and service sector firms with more than 50 employees, a subjective profit measure of the form "How does this site's financial performance, that is, profitability, compare with other establishments in the same industry?" (with responses on a 5-point scale), and an objective measure of profit measured as pretax financial value of sales less costs per employee. In both studies the authors demonstrate that the subjective measures of company performance display convergent validity, discriminant validity, and construct validity.

${ }^{8}$ Consistent with this line of argument, Machin and Stewart 1996) have shown the subjective financial performance measure in the WIRS to be a good predictor of workplace closure.

${ }^{9}$ Apart from tractability, another advantage of aggregating the information on teams to the binary level is that it mitigates one of the measurement issues in this analysis. Since the teams question is asked with reference to the establishment's largest occupational group, and since we do not observe what percentage of the establishment's workforce is employed in the largest occupational group, the information on the percentage of workers engaged in teams is misleading. For example, suppose that Establishment A (employing 100 workers) has 20 workers in its largest occupational group and that Establishment B (also employing 100 workers) has 30 workers in its largest occupational group. Suppose that Establishment A responds that "Almost All (80-99\%)" of its workers in the largest occupational group are organized in teams and that Establishment B responds "Most (60-79\%)" to the same question. Then 16-20 workers are in teams in Establishment A and $18-24$ workers are in teams in Establishment $\mathrm{B}$, and it is unclear which of these establishments makes greater use of team production. My approach of aggregating the teams variable amounts to comparing the performance of establishments such as A and B to those that use no team production at all in the largest occupational group.

${ }^{10}$ Although my model allows for a full set of interactions of the teams treatment with other observed and unobserved determinants of financial performance, the autonomy treatment is restricted to an intercept shift. An even less restrictive approach than mine would allow both the teams and autonomy treatments to interact with all firm characteristics, in which case financial performance would be a three-equation switching model. I view the approach taken here as a compromise, given data and computational constraints and the fact that theory and previous empirical work suggests that allowing for teams interactions is of first-order importance.

${ }^{11}$ I know of no empirical study in which just-in-time was included as a determinant of financial performance, even though some of these studies used WERS and had the variable available for inclusion (Machin and Stewart 1990, 1996; McNabb and Whitfield 1997, 1998).

${ }^{12}$ Among other places, this is argued in Baron and Kreps (1999). Following their measured endorsement of granting autonomy to teams (see their quote that opened this paper) they append the following footnote describing the necessary preconditions for granting autonomy to be beneficial. "Of course, this takes as given that team members have internalized the organization's goals and possess the information and resources (including training) necessary to manage themselves effectively. If these conditions are not satisfied, then the management involved has been derelict in establishing the preconditions for a [self-managed or autonomous] team to work effectively." Baron and Kreps (1999)

${ }^{13}$ Note that the only covariates in the model that are "continuous", in the usual sense, are establishment size and the fraction of employees who work part time. However, the model also includes several variables recorded in the survey as ordered discrete categories. These include information, incentive alignment, and decisions (5 categories each); work at home (6 categories); multi-skilling and off-site training (7 categories each); and number of recognized unions (11 categories). To economize on the number of parameters to be estimated, I treat each of these variables as continuous indexes rather than creating multiple dummies for each category. In unreported sensitivity checks I found the same qualitative results in models that include these variables as multiple dummies rather than as "continuous" indexes.

${ }^{14}$ In the Appendix I state the precise formulae for computing these effects.

${ }^{15}$ While this is an intuitive univariate measure for ranking the workplaces and seems the most natural default, it is by no means unique. Furthermore, it assumes symmetry in the loss function. For example, one workplace might have Effect $\mathrm{A} 3=0.10$ and Effect $\mathrm{A} 1=-0.07$, whereas another might have Effect $\mathrm{A} 3=0.07$ and Effect $\mathrm{A} 1=-0.10$. 
Both are ranked the same by the criterion Effect A3 - Effect A1. A different ranking might assign more weight to increases in the probability of being in the highest category or, alternatively, to decreases in the probability of being in the lowest category.

${ }^{16}$ The issue of how the predicted benefits of teams to financial performance varies by firm characteristics is addressed in DeVaro and Kurtulus (2005).

${ }^{17}$ In the Appendix I state the formulae for computing these effects.

${ }^{18}$ At all quantiles considered, the point estimates reveal a more beneficial (or less detrimental) effect for nonautonomous than for autonomous teams. The picture that emerges for the typical establishment is that, while team production enhances financial performance, there is no added benefit from granting team autonomy. In one-tailed tests at each of the three quantiles of (Effect A3 - Effect A1), the null hypothesis that (Effect D3 - Effect D1) = 0 cannot be rejected at the ten percent significance level. This null states that the predicted benefit from team production is the same whether autonomous or non-autonomous teams are used. Therefore, the statistical evidence that non-autonomous or closely managed teams are actually better than autonomous teams is weak.

${ }^{19}$ All results of the paper that are discussed but not reported are available from the author upon request.

${ }^{20} \mathrm{My}$ rationale for reporting results from the more parsimonious specification is driven mainly by computational considerations. Convergence of the model is easier to achieve in the more parsimonious specification. This becomes an issue when conducting statistical inference, since I use the parametric bootstrap to compute standard errors and must therefore estimate the model a large number of times.

${ }^{21}$ Bryson and Wilkinson (2002) showed the sensitivity of union effects to the different subsamples corresponding to alternative interpretations of financial performance. In principle, the same approach could be used in the teams context if there were enough observations in the various subsamples. Since only the "profit or value added" category is large enough to estimate the model, the best that I can do is to compare these results to estimates from the full sample that aggregates all interpretations of financial performance. The comparison is interesting, in part because it has implications for the interpretation of results from studies that used the financial performance measure in earlier waves of the WIRS.

${ }^{22}$ Teams might raise profits more than productivity if, for example, they also save on factor costs. While this is consistent with the data, most theories of teams suggest higher wages, which is inconsistent with that hypothesis. The possibility that teams might reduce input costs could arise to the extent that workers value the social interactions associated with team production, suggesting a compensating differential in which workers in teams are willing to accept lower compensation in exchange for the opportunity to work in teams. A case study supportive of this argument is the Hamilton, Nickerson, and Owan (2003) analysis of a garment manufacturing plant, where it was found that higher-ability workers were the first to self-select voluntarily into teams (paid on the basis of group piece rates) even though this often resulted in lower earnings than these workers had received under the individual piece rate scheme before entering teams. The authors interpreted this finding as consistent with the existence of nonpecuniary benefits of working in teams.

${ }^{23}$ When Tables 1-4 are computed on exactly the same sample that is used in estimation, they are virtually identical to the reported versions of these tables. 
Table 1: Distribution of Workplaces by Industry and Largest Occupational Group

\begin{tabular}{|c|c|c|}
\hline & $\%$ (unweighted) & $\%$ (weighted) \\
\hline \multicolumn{3}{|l|}{ Distribution by Industry } \\
\hline Manufacturing & 19.5 & 19.7 \\
\hline Electricity, Gas, and Water & 4.5 & 0.25 \\
\hline Construction & 7.0 & 5.0 \\
\hline Wholesale and Retail & 17.8 & 23.4 \\
\hline Hotels and Restaurants & 7.2 & 9.1 \\
\hline Transport and Communication & 7.4 & 3.7 \\
\hline Financial Services & 6.2 & 3.8 \\
\hline Other Business Services & 13.1 & 14.9 \\
\hline Public Administration & 2.3 & 0.81 \\
\hline Education & 7.1 & 10.6 \\
\hline Health & 4.5 & 6.5 \\
\hline Other Community Services & 3.3 & 2.4 \\
\hline Total & $100 \%$ & $100 \%$ \\
\hline \multicolumn{3}{|l|}{ Distribution by Largest Occupational Group } \\
\hline Managers \& Administrators & 0.6 & 0.5 \\
\hline Professional Occupations & 10.2 & 9.2 \\
\hline Associate Professional \& Technical Occupations & 6.7 & 5.6 \\
\hline Clerical \& Secretarial Occupations & 17.2 & 15.7 \\
\hline Craft \& Related Occupations & 12.9 & 15.0 \\
\hline Personal \& Protective Service Occupations & 10.4 & 16.0 \\
\hline Sales Occupations & 12.9 & 12.4 \\
\hline Plant \& Machine Operatives & 18.4 & 16.8 \\
\hline Other Occupations & 10.6 & 8.7 \\
\hline Total & $100 \%$ & $100 \%$ \\
\hline
\end{tabular}

Note: Tabulations are for the subsample of 952 establishments interpreting financial performance as "profit or value added." 
Table 2: Distribution of Financial Performance by $\%$ of Largest Occupational Group in Teams

\begin{tabular}{l|l|l|l|l|l|l}
$0 \%$ & $1-19 \%$ & $20-39 \%$ & $40-59 \%$ & $60-79 \%$ & $80-99 \%$ & $100 \%$ \\
\hline
\end{tabular}

\begin{tabular}{|c|c|c|c|c|c|c|c|}
\hline \multicolumn{8}{|c|}{ Distribution of Financial Performance (unweighted) } \\
\hline A lot below average & 0.9 & 0.0 & 2.4 & 2.0 & 0.0 & 0.0 & 0.0 \\
\hline Below average & 4.3 & 8.3 & 7.3 & 7.8 & 5.4 & 7.7 & 4.5 \\
\hline About average for industry & 40.8 & 33.3 & 34.1 & 27.5 & 30.4 & 25.6 & 33.8 \\
\hline Better than average & 39.1 & 43.3 & 50.0 & 39.2 & 50.0 & 49.2 & 36.8 \\
\hline A lot better than average & 14.8 & 15.0 & 6.1 & 23.5 & 14.3 & 17.4 & 24.9 \\
\hline Column sum & $100 \%$ & $100 \%$ & $100 \%$ & $100 \%$ & $100 \%$ & $100 \%$ & $100 \%$ \\
\hline \multicolumn{8}{|c|}{ Distribution of Financial Performance (weighted) } \\
\hline A lot below average & 0.3 & 0.0 & 5.6 & 1.4 & 0.0 & 0.0 & 0.0 \\
\hline Below average & 5.6 & 5.2 & 5.1 & 15.0 & 9.8 & 5.0 & 5.7 \\
\hline About average for industry & 35.8 & 37.7 & 34.6 & 40.8 & 34.5 & 26.5 & 37.8 \\
\hline Better than average & 51.0 & 51.1 & 33.9 & 30.4 & 37.0 & 49.1 & 32.5 \\
\hline A lot better than average & 7.4 & 6.0 & 20.9 & 12.4 & 18.7 & 19.4 & 24.0 \\
\hline Column sum & $100 \%$ & $100 \%$ & $100 \%$ & $100 \%$ & $100 \%$ & $100 \%$ & $100 \%$ \\
\hline
\end{tabular}

Note: Column categories represent the fraction of the largest occupational group that is engaged in team production. Row categories represent the financial performance of the establishment relative to the industry average, as reported by the respondent manager. Sample size is 949 establishments interpreting financial performance as "profit or value added." 
Table 3: Financial Performance by $\%$ of Largest Occupational Group in Autonomous Teams \begin{tabular}{l|l|l|l|l|l|l}
$1-19 \%$ & $20-39 \%$ & $40-59 \%$ & $60-79 \%$ & $80-99 \%$ & $100 \%$ \\
\hline
\end{tabular}

Distribution of Financial Performance Given Autonomous Teams (unweighted)

\begin{tabular}{l|c|c|c|c|c|c}
\hline A lot below average & 0.0 & 2.4 & 0.0 & 0.0 & 0.0 & 0.0 \\
\hline Below average & 6.3 & 9.5 & 4.3 & 10.5 & 4.7 & 5.2 \\
\hline About average for industry & 37.5 & 38.1 & 30.4 & 29.8 & 26.2 & 33.5 \\
\hline Better than average & 46.9 & 45.2 & 47.8 & 49.1 & 45.8 & 37.2 \\
\hline A lot better than average & 9.4 & 4.8 & 17.4 & 10.5 & 23.4 & 24.1 \\
\hline \multicolumn{1}{r|}{ Column sum } & $100 \%$ & $100 \%$ & $100 \%$ & $100 \%$ & $100 \%$ & $100 \%$ \\
\hline \hline
\end{tabular}

Distribution of Financial Performance Given Autonomous Teams (weighted)

\begin{tabular}{l|c|c|c|c|c|c}
\hline A lot below average & 0.0 & 9.5 & 0.0 & 0.0 & 0.0 & 0.0 \\
\hline Below average & 2.5 & 7.8 & 17.3 & 15.6 & 1.9 & 4.9 \\
\hline About average for industry & 34.6 & 20.8 & 45.8 & 38.8 & 26.0 & 41.6 \\
\hline Better than average & 60.9 & 35.1 & 32.0 & 35.0 & 53.4 & 29.7 \\
\hline A lot better than average & 2.1 & 26.8 & 4.8 & 10.6 & 18.7 & 23.7 \\
\hline \multicolumn{1}{r|}{ Column sum } & $100 \%$ & $100 \%$ & $100 \%$ & $100 \%$ & $100 \%$ & $100 \%$ \\
\hline
\end{tabular}

Note: Column categories represent the fraction of the largest occupational group that is engaged in team production, given that teams are used and granted autonomy. Row categories represent the financial performance of the establishment relative to the industry average, as reported by the respondent manager. Autonomy is defined as granting team members discretion over how their work is to be done. Sample size is 452 . 
Table 4: Cell Frequencies for FINPER, TEAMS, and AUTO

Autonomy Measure 1: Team Members Jointly Decide How the Work is to be Done Analysis Sample $(\mathrm{N}=949) \quad$ Full Sample $(\mathrm{N}=1851)$ (unweighted)

\begin{tabular}{|c|c|c|c|c|c|c|}
\hline FINPER = & 1 & 2 & 3 & 1 & 2 & 3 \\
\hline$T E A M S=0$ & 0.14 & 0.11 & 0.10 & 0.15 & 0.11 & 0.13 \\
\hline$T E A M S=1, A U T O=0$ & 0.38 & 0.41 & 0.41 & 0.36 & 0.40 & 0.40 \\
\hline$T E A M S=1, A U T O=1$ & 0.48 & 0.47 & 0.49 & 0.49 & 0.50 & 0.47 \\
\hline \multicolumn{7}{|c|}{ (weighted) } \\
\hline FINPER $=$ & 1 & 2 & 3 & 1 & 2 & 3 \\
\hline$T E A M S=0$ & 0.22 & 0.29 & 0.10 & 0.25 & 0.27 & 0.17 \\
\hline$T E A M S=1, A U T O=0$ & 0.27 & 0.26 & 0.39 & 0.27 & 0.25 & 0.33 \\
\hline$T E A M S=1, A U T O=1$ & 0.51 & 0.46 & 0.51 & 0.48 & 0.48 & 0.50 \\
\hline
\end{tabular}

Autonomy Measure 2: Team Members Are Able to Appoint Their Own Team Leaders Analysis Sample ( $=945) \quad$ Full Sample $(\mathrm{N}=1847)$

(unweighted)

\begin{tabular}{|l|c|c|c|}
\hline \multicolumn{1}{|c|}{ FINPER $=$} & 1 & 2 & 3 \\
\hline TEAMS $=0$ & 0.14 & 0.12 & 0.10 \\
\hline TEAMS $=1$, AUTO $=0$ & 0.79 & 0.81 & 0.82 \\
\hline TEAMS $=1$, AUTO $=1$ & 0.07 & 0.07 & 0.08 \\
\hline
\end{tabular}

\begin{tabular}{c|c|c|}
\hline 1 & 2 & 3 \\
\hline 0.15 & 0.11 & 0.13 \\
\hline 0.78 & 0.83 & 0.80 \\
\hline 0.07 & 0.06 & 0.07 \\
\hline
\end{tabular}

\begin{tabular}{|l|c|c|c}
\hline \multicolumn{1}{|c|}{ FINPER $=$} & 1 & 2 & 3 \\
\hline TEAM $S=0$ & 0.22 & 0.29 & 0.10 \\
\hline TEAMS $=1$, AUTO $=0$ & 0.70 & 0.66 & 0.77 \\
\hline TEAMS $=1$, AUTO $=1$ & 0.08 & 0.05 & 0.13 \\
\hline
\end{tabular}

\begin{tabular}{c|c|c|}
\hline 1 & 2 & 3 \\
\hline 0.25 & 0.27 & 0.17 \\
\hline 0.68 & 0.67 & 0.72 \\
\hline 0.07 & 0.07 & 0.11 \\
\hline
\end{tabular}

Autonomy Measure 3: Teams Are Given Responsibility for Specific Products or Services Analysis Sample $(\mathrm{N}=947) \quad$ Full Sample $(\mathrm{N}=1848)$

(unweighted)

\begin{tabular}{|l|c|c|c}
\hline \multicolumn{1}{|c|}{ FINPER $=$} & 1 & 2 & 3 \\
\hline TEAMS $=0$ & 0.14 & 0.12 & 0.10 \\
\hline TEAMS $=1$, AUTO $=0$ & 0.14 & 0.14 & 0.13 \\
\hline TEAMS $=1$, AUTO $=1$ & 0.72 & 0.75 & 0.77 \\
\hline
\end{tabular}

\begin{tabular}{c|c|c|}
\hline 1 & 2 & 3 \\
\hline 0.15 & 0.11 & 0.13 \\
\hline 0.12 & 0.12 & 0.11 \\
\hline 0.73 & 0.78 & 0.75 \\
\hline
\end{tabular}

\begin{tabular}{|l|c|c|c}
\hline \multicolumn{1}{|c|}{ FINPER $=$} & 1 & 2 & 3 \\
\hline TEAMS $=0$ & 0.22 & 0.29 & 0.10 \\
\hline TEAMS $=1$, AUTO $=0$ & 0.11 & 0.19 & 0.09 \\
\hline TEAMS $=1$, AUTO $=1$ & 0.67 & 0.52 & 0.81 \\
\hline
\end{tabular}

\begin{tabular}{c|c|c|}
\hline 1 & 2 & 3 \\
\hline 0.25 & 0.27 & 0.17 \\
\hline 0.11 & 0.14 & 0.12 \\
\hline 0.64 & 0.59 & 0.71 \\
\hline
\end{tabular}


Table 5: Descriptive Statistics for Variables in Structural Teams Model (unweighted) (weighted)

\begin{tabular}{|c|c|c|c|c|}
\hline & Mean & \begin{tabular}{|l} 
Standard \\
Deviation
\end{tabular} & Mean & $\begin{array}{l}\text { Standard } \\
\text { Deviation }\end{array}$ \\
\hline \multicolumn{5}{|l|}{ Dependent Variables } \\
\hline Financial Performance & 1.803 & 0.732 & 1.758 & 1.414 \\
\hline Teams & 0.878 & 0.328 & 0.772 & 0.891 \\
\hline Autonomy (1) & 0.547 & 0.498 & 0.632 & 1.007 \\
\hline Autonomy (2) & 0.083 & 0.276 & 0.096 & 0.680 \\
\hline Autonomy (3) & 0.844 & 0.363 & 0.822 & 0.878 \\
\hline \multicolumn{5}{|l|}{ Firm Controls } \\
\hline Single-Establishment Firm & 0.223 & 0.416 & 0.367 & 0.994 \\
\hline Establishment Size & 267.6 & 608.0 & 60.922 & 109.8 \\
\hline Fraction of Part Time Workers & 0.228 & 0.282 & 0.265 & 0.602 \\
\hline Temporary Workers & 0.396 & 0.489 & 0.218 & 0.738 \\
\hline Fixed Term Workers Under One Year & 0.412 & 0.492 & 0.235 & 0.771 \\
\hline Fixed Term Workers Over One Year & 0.177 & 0.382 & 0.128 & 0.652 \\
\hline Union Workers & 0.563 & 0.496 & 0.363 & 0.926 \\
\hline Private Sector Franchise & 0.017 & 0.129 & 0.012 & 0.120 \\
\hline Private Sector Non-franchise & 0.503 & 0.500 & 0.359 & 0.917 \\
\hline Alternative Private Sector Franchise & 0.012 & 0.110 & 0.037 & 0.429 \\
\hline Alternative Private Sector Non-franchise & 0.343 & 0.475 & 0.483 & 0.993 \\
\hline Financial Participation & 0.757 & 0.429 & 0.641 & 0.974 \\
\hline Owner Manager & 0.113 & 0.317 & 0.189 & 0.804 \\
\hline Foreign Owned & 0.148 & 0.355 & 0.079 & 0.394 \\
\hline Operation Over Five Years & 0.895 & 0.307 & 0.890 & 0.606 \\
\hline Multi-skilling & 3.140 & 1.850 & 3.238 & 4.561 \\
\hline Number of Recognized Unions & 1.134 & 1.635 & 0.602 & 2.065 \\
\hline Induction Training & 0.835 & 0.371 & 0.697 & 0.977 \\
\hline Off-site Training & 3.881 & 2.009 & 3.364 & 4.266 \\
\hline Just-in-time Production & 0.366 & 0.482 & 0.333 & 0.935 \\
\hline Information & 2.708 & 1.083 & 2.525 & 2.120 \\
\hline Incentive Alignment & 2.290 & 0.828 & 2.192 & 1.716 \\
\hline Decisions & 3.656 & 1.010 & 3.615 & 1.933 \\
\hline Work at Home & 5.386 & 0.868 & 5.513 & 1.627 \\
\hline \multicolumn{5}{|c|}{$\begin{array}{l}\text { Note: These statistics are computed from the subsample of } 889 \text { establishments on which the } \\
\text { structural model is estimated. These are the establishments that interpret financial performance as } \\
\text { synonymous with profit or value added and for which complete data are available on all variables of } \\
\text { the model. Autonomy (1) is the main autonomy variable in the study, defined by team members } \\
\text { jointly deciding how the work is done. Autonomy (2) indicates that the team has authority to appoint } \\
\text { its own leaders and (3) indicates that it has responsibility for specific products or services. }\end{array}$} \\
\hline
\end{tabular}


Table 6: Estimates from Structural Teams Model

\begin{tabular}{|c|c|c|c|c|}
\hline & FINPER* $(T E A M S=1)$ & FINPER* $(T E A M S=0)$ & TEAMS* & $A U T O *$ \\
\hline AUTO (1) & $\begin{array}{c}1.086 \\
(0.443)^{* *}\end{array}$ & $\bullet$ & $\bullet$ & $\bullet$ \\
\hline Single-Establishment Firm & $\begin{array}{c}0.173 \\
(0.153)\end{array}$ & $\begin{array}{l}-0.353 \\
(0.317)\end{array}$ & $\begin{array}{c}-0.341 \\
(0.218)\end{array}$ & $\begin{array}{c}-0.343 \\
(0.220)\end{array}$ \\
\hline Establishment Size & $\begin{array}{c}0.004 \\
(0.009)\end{array}$ & $\begin{array}{c}0.054 \\
(0.069) \\
\end{array}$ & $\begin{array}{c}0.030 \\
(0.026)\end{array}$ & $\begin{array}{c}-0.012 \\
(0.015)\end{array}$ \\
\hline Fraction of Part Time Workers & $\begin{array}{c}0.232 \\
(0.187) \\
\end{array}$ & $\begin{array}{l}-0.149 \\
(0.441)\end{array}$ & $\begin{array}{c}0.141 \\
(0.237) \\
\end{array}$ & $\begin{array}{c}-0.117 \\
(0.179) \\
\end{array}$ \\
\hline Temporary Workers & $\begin{array}{c}0.124 \\
(0.110)\end{array}$ & $\begin{array}{c}0.254 \\
(0.347)\end{array}$ & $\begin{array}{c}0.273 \\
(0.202) \\
\end{array}$ & $\begin{array}{c}-0.251 \\
(0.180) \\
\end{array}$ \\
\hline Fixed Term Workers Under One Year & $\begin{array}{c}-0.003 \\
(0.079)\end{array}$ & $\begin{array}{c}-0.221 \\
(0.293)\end{array}$ & $\begin{array}{c}0.220 \\
(0.156)\end{array}$ & $\begin{array}{c}-0.008 \\
(0.093)\end{array}$ \\
\hline Fixed Term Workers Over One Year & $\begin{array}{l}-0.071 \\
(0.121)\end{array}$ & $\begin{array}{l}-0.267 \\
(0.379)\end{array}$ & $\begin{array}{c}0.235 \\
(0.206)\end{array}$ & $\begin{array}{c}0.359 \\
(0.200)^{*}\end{array}$ \\
\hline Union Workers & $\begin{array}{c}0.064 \\
(0.098)\end{array}$ & $\begin{array}{c}0.196 \\
(0.332)\end{array}$ & $\begin{array}{c}0.158 \\
(0.157)\end{array}$ & $\begin{array}{c}0.072 \\
(0.114)\end{array}$ \\
\hline Private Sector Franchise & $\begin{array}{c}0.375 \\
(0.403)^{*}\end{array}$ & $\begin{array}{c}-2.642 \\
(0.692)^{* *}\end{array}$ & $\begin{array}{c}0.547 \\
(1.708) \\
\end{array}$ & $\begin{array}{c}-0.477 \\
(0.479) \\
\end{array}$ \\
\hline Private Sector Non-Franchise & $\begin{array}{c}0.119 \\
(0.169)\end{array}$ & $\begin{array}{c}0.206 \\
(0.783)\end{array}$ & $\begin{array}{c}0.037 \\
(0.203)\end{array}$ & $\begin{array}{l}-0.062 \\
(0.164)\end{array}$ \\
\hline Alternative Private Sector Franchise & $\begin{array}{c}0.170 \\
(0.412) \\
\end{array}$ & $\begin{array}{c}0.818 \\
(1.740) \\
\end{array}$ & $\begin{array}{c}-0.070 \\
(1.042) \\
\end{array}$ & $\begin{array}{c}-0.619 \\
(0.855) \\
\end{array}$ \\
\hline Alternative Private Sector Non-Franchise & $\begin{array}{l}-0.227 \\
(0.198)\end{array}$ & $\begin{array}{c}0.639 \\
(0.886)\end{array}$ & $\begin{array}{c}0.109 \\
(0.245)\end{array}$ & $\begin{array}{c}0.228 \\
(0.219)\end{array}$ \\
\hline Financial Participation & $\begin{array}{c}0.189 \\
(0.130)\end{array}$ & $\begin{array}{c}0.033 \\
(0.255)\end{array}$ & & \\
\hline Owner Manager & $\begin{array}{c}0.093 \\
(0.128) \\
\end{array}$ & $\begin{array}{c}-0.306 \\
(0.334) \\
\end{array}$ & & \\
\hline Foreign Owned & $\begin{array}{c}-0.162 \\
(0.118) \\
\end{array}$ & $\begin{array}{c}-0.337 \\
(0.417) \\
\end{array}$ & & \\
\hline Operation Over Five Years & $\begin{array}{l}-0.009 \\
(0.109)\end{array}$ & $\begin{array}{c}0.344 \\
(0.490)\end{array}$ & & \\
\hline Multi-Skilling & $\begin{array}{c}0.019 \\
(0.020) \\
\end{array}$ & $\begin{array}{c}-0.008 \\
(0.055) \\
\end{array}$ & & \\
\hline Number of Recognized Unions & $\begin{array}{l}-0.077^{*} \\
(0.042)\end{array}$ & $\begin{array}{l}-0.007 \\
(0.142)\end{array}$ & & \\
\hline Induction Training & $\begin{array}{c}-0.094 \\
(0.102) \\
\end{array}$ & $\begin{array}{c}-0.407 \\
(0.284) \\
\end{array}$ & & \\
\hline Off-Site Training & $\begin{array}{c}0.025 \\
(0.020) \\
\end{array}$ & $\begin{array}{c}-0.010 \\
(0.046) \\
\end{array}$ & & \\
\hline Just-in-Time Production & $\bullet$ & $\bullet$ & $\begin{array}{c}0.317 \\
(0.198) \\
\end{array}$ & $\bullet$ \\
\hline Information & $\bullet$ & $\bullet$ & $\bullet$ & $\begin{array}{c}0.084 \\
(0.055) \\
\end{array}$ \\
\hline Incentive Alignment & $\bullet$ & $\bullet$ & $\bullet$ & $\begin{array}{c}-0.279 \\
(0.145)^{*}\end{array}$ \\
\hline Decisions & $\bullet$ & $\bullet$ & $\bullet$ & $\begin{array}{c}0.046 \\
(0.055) \\
\end{array}$ \\
\hline Work at Home & $\bullet$ & $\bullet$ & $\bullet$ & -0.089 \\
\hline
\end{tabular}




\begin{tabular}{|c|c|c|c|c|}
\hline & & & & \multirow[b]{2}{*}{$(0.069)$} \\
\hline & & & & \\
\hline Constant & $\begin{array}{l}-0.670 \\
(0.410)\end{array}$ & $\begin{array}{c}0.977 \\
(1.106) \\
\end{array}$ & $\begin{array}{c}0.708 \\
(0.327)^{* *}\end{array}$ & $\begin{array}{c}0.973 \\
(0.667) \\
\end{array}$ \\
\hline $\mathrm{c}$ & & $\begin{array}{c}0.993 \\
(0.107) \\
\end{array}$ & & \\
\hline$\sigma_{02}$ & & $\begin{array}{c}0.691 \\
(0.227)^{* *} \\
\end{array}$ & & \\
\hline$\sigma_{12}$ & & $\begin{array}{c}0.267 \\
(0.630)\end{array}$ & & \\
\hline$\sigma_{13}$ & & $\begin{array}{c}-0.729 \\
(0.210)^{* *}\end{array}$ & & \\
\hline$\sigma_{23}$ & & $\begin{array}{c}-0.127 \\
(0.834)\end{array}$ & & \\
\hline
\end{tabular}

Note: Standard errors from the parametric bootstrap are in parentheses and are based on 100 bootstrap replications. See Appendix for details. $*$ and $* *$ indicate significance at the $10 \%$ and $5 \%$ levels, respectively. Sample size is 893 . 
Table 7

Effect of Team Production on Financial Performance of Three Selected Workplaces

AUTO $=$ Team Members Jointly Decide How the Work is to be Done

Panel 1: Results for workplace at the 0.25 quantile of the distribution of predicted benefits of teams to financial performance; that is, the 0.25 quantile of (Effect A3 - Effect A1).

\begin{tabular}{l|c|c|c|c}
\hline $\begin{array}{l}\text { Financial } \\
\text { performance is ... }\end{array}$ & All Teams & $\begin{array}{c}\text { Autonomous } \\
\text { Teams }\end{array}$ & $\begin{array}{c}\text { Non-Autonomous } \\
\text { Teams }\end{array}$ & Difference \\
\hline average or below & 0.040 & 0.046 & 0.032 & 0.014 \\
$(0.070)$ & $(0.076)$ & $(0.072)$ & $(0.043)$ \\
\hline better than average & 0.004 & 0.002 & 0.005 & -0.003 \\
& $(0.080)$ & $(0.084)$ & $(0.081)$ & $(0.036)$ \\
\hline a lot better than & -0.043 & -0.048 & -0.038 & -0.011 \\
average & $(0.068)$ & $(0.071)$ & $(0.070)$ & $(0.035)$ \\
\hline
\end{tabular}

Panel 2: Results for workplace at the median of the distribution of predicted benefits of teams to financial performance; that is, the median of (Effect A3 - Effect A1).

\begin{tabular}{l|c|c|c|c}
\hline $\begin{array}{l}\text { Financial } \\
\text { performance is ... }\end{array}$ & All Teams & $\begin{array}{c}\text { Autonomous } \\
\text { Teams }\end{array}$ & $\begin{array}{c}\text { Non-Autonomous } \\
\text { Teams }\end{array}$ & Difference \\
\hline average or below & -0.089 & -0.081 & -0.096 & 0.016 \\
$(0.075)$ & $(0.077)$ & $(0.081)$ & $(0.047)$ \\
\hline better than average & 0.001 & 0.002 & 0.000 & 0.002 \\
$(0.079)$ & $(0.083)$ & $(0.078)$ & $(0.035)$ \\
\hline a lot better than & $0.087^{*}$ & 0.079 & $0.096^{*}$ & -0.017 \\
average & $(0.049)$ & $(0.053)$ & $(0.051)$ & $(0.035)$ \\
\hline
\end{tabular}

Panel 3: Results for workplace at 0.75 quantile of the distribution of predicted benefits of teams to financial performance; that is, the 0.75 quantile of (Effect A3 - Effect A1).

\begin{tabular}{l|c|c|c|c}
\hline $\begin{array}{l}\text { Financial } \\
\text { performance is ... }\end{array}$ & All Teams & $\begin{array}{c}\text { Autonomous } \\
\text { Teams }\end{array}$ & $\begin{array}{c}\text { Non-Autonomous } \\
\text { Teams }\end{array}$ & Difference \\
\hline average or below & $-0.230^{* *}$ & $-0.213^{* *}$ & $-0.282^{* *}$ & 0.069 \\
$(0.106)$ & $(0.105)$ & $(0.113)$ & $(0.048)$ \\
\hline better than average & 0.058 & 0.046 & 0.094 & -0.048 \\
$(0.125)$ & $(0.128)$ & $(0.125)$ & $(0.041)$ \\
\hline a lot better than & $0.172^{* *}$ & $0.167^{* *}$ & $0.188^{* *}$ & -0.021 \\
average & $(0.059)$ & $(0.064)$ & $(0.062)$ & $(0.038)$ \\
\hline
\end{tabular}

Notes: Cell entries denote the effect of team production on the probability that financial performance is at or below, better than, or a lot better than the industry average. That is, for the first three columns, cell entries display the change in the predicted probability that financial performance is [row heading] for the industry, given that [column heading] are used. The fourth column is the second less the third. Standard errors from the parametric bootstrap (100 replications) are in parentheses. $*$ and $* *$ denote statistical significance at the $10 \%$ and $5 \%$ levels, respectively. 
Table 8

Effect of Team Production on Financial Performance of Three Selected Workplaces AUTO $=$ Team Members Are Able to Appoint Their Own Team Leaders

Panel 1: Results for workplace at the 0.25 quantile of the distribution of predicted benefits of teams to financial performance; that is, the 0.25 quantile of (Effect A3 - Effect A1).

\begin{tabular}{l|c|c|c|c}
\hline $\begin{array}{l}\text { Financial } \\
\text { performance is ... }\end{array}$ & All Teams & $\begin{array}{c}\text { Autonomous } \\
\text { Teams }\end{array}$ & $\begin{array}{c}\text { Non-Autonomous } \\
\text { Teams }\end{array}$ & Difference \\
\hline average or below & 0.056 & 0.004 & 0.063 & -0.059 \\
$(0.108)$ & $(0.150)$ & $(0.110)$ & $(0.126)$ \\
\hline better than average & -0.034 & -0.001 & -0.039 & 0.038 \\
$(0.097)$ & $(0.108)$ & $(0.098)$ & $(0.077)$ \\
\hline a lot better than & -0.022 & -0.004 & -0.024 & 0.021 \\
average & $(0.075)$ & $(0.105)$ & $(0.074)$ & $(0.075)$ \\
\hline
\end{tabular}

Panel 2: Results for workplace at the median of the distribution of predicted benefits of teams to financial performance; that is, the median of (Effect A3 - Effect A1).

\begin{tabular}{l|c|c|c|c}
\hline $\begin{array}{l}\text { Financial } \\
\text { performance is ... }\end{array}$ & All Teams & $\begin{array}{c}\text { Autonomous } \\
\text { Teams }\end{array}$ & $\begin{array}{c}\text { Non-Autonomous } \\
\text { Teams }\end{array}$ & Difference \\
\hline average or below & -0.111 & -0.124 & -0.109 & -0.015 \\
$(0.092)$ & $(0.131)$ & $(0.094)$ & $(0.114)$ \\
\hline better than average & 0.062 & 0.084 & 0.060 & 0.024 \\
$(0.099)$ & $(0.107)$ & $(0.100)$ & $(0.076)$ \\
\hline a lot better than & 0.049 & 0.041 & 0.049 & -0.009 \\
average & $(0.062)$ & $(0.100)$ & $(0.061)$ & $(0.094)$ \\
\hline
\end{tabular}

Panel 3: Results for workplace at the 0.75 quantile of the distribution of predicted benefits of teams to financial performance; that is, the 0.75 quantile of (Effect A3 - Effect A1).

\begin{tabular}{l|c|c|c|c}
\hline & All Teams & $\begin{array}{c}\text { Autonomous } \\
\text { Teams }\end{array}$ & $\begin{array}{c}\text { Non-Autonomous } \\
\text { Teams }\end{array}$ & Difference \\
\hline average or below & $-0.219^{* *}$ & $-0.235^{*}$ & $-0.218^{* *}$ & -0.017 \\
$(0.095)$ & $(0.129)$ & $(0.097)$ & $(0.107)$ \\
\hline \multirow{2}{*}{ better than average } & 0.047 & 0.075 & 0.046 & 0.029 \\
& $(0.111)$ & $(0.108)$ & $(0.112)$ & $(0.080)$ \\
\hline a lot better than & $0.172^{* *}$ & 0.160 & $0.172^{* *}$ & -0.012 \\
average & $(0.059)$ & $(0.100)$ & $(0.057)$ & $(0.075)$ \\
\hline
\end{tabular}

Notes: Cell entries denote the effect of team production on the probability that financial performance is at or below, better than, or a lot better than the industry average. That is, for the first three columns, cell entries display the change in the predicted probability that financial performance is [row heading] for the industry, given that [column heading] are used. The fourth column is the second less the third. Standard errors from the parametric bootstrap (100 replications) are in parentheses. * and ** denote statistical significance at the $10 \%$ and $5 \%$ levels, respectively. 
Table 9

Effect of Team Production on Financial Performance of Three Selected Workplaces

AUTO $=$ Teams are Given Responsibility for Specific Products or Services

Panel 1: Results for workplace at the 0.25 quantile of the distribution of predicted benefits of teams to financial performance; that is, the 0.25 quantile of (Effect A3 - Effect A1).

\begin{tabular}{l|c|c|c|c}
\hline $\begin{array}{l}\text { Financial } \\
\text { performance is ... }\end{array}$ & All Teams & $\begin{array}{c}\text { Autonomous } \\
\text { Teams }\end{array}$ & $\begin{array}{c}\text { Non-Autonomous } \\
\text { Teams }\end{array}$ & Difference \\
\hline average or below & 0.054 & 0.054 & 0.054 & 0.000 \\
$(0.070)$ & $(0.071)$ & $(0.087)$ & $(0.062)$ \\
\hline better than average & -0.037 & -0.038 & -0.024 & -0.014 \\
& $(0.070)$ & $(0.069)$ & $(0.079)$ & $(0.038)$ \\
\hline a lot better than & -0.017 & -0.016 & -0.030 & 0.014 \\
average & $(0.068)$ & $(0.069)$ & $(0.074)$ & $(0.040)$ \\
\hline
\end{tabular}

Panel 2: Results for workplace at the median of the distribution of predicted benefits of teams to financial performance; that is, the median of (Effect A3 - Effect A1).

\begin{tabular}{l|c|c|c|c}
\hline $\begin{array}{l}\text { Financial } \\
\text { performance is ... }\end{array}$ & All Teams & $\begin{array}{c}\text { Autonomous } \\
\text { Teams }\end{array}$ & $\begin{array}{c}\text { Non-Autonomous } \\
\text { Teams }\end{array}$ & Difference \\
\hline average or below & -0.087 & -0.075 & -0.108 & 0.033 \\
$(0.078)$ & $(0.078)$ & $(0.095)$ & $(0.065)$ \\
\hline better than average & 0.007 & 0.002 & 0.017 & -0.016 \\
$(0.079)$ & $(0.080)$ & $(0.078)$ & $(0.038)$ \\
\hline a lot better than & $0.079 *$ & 0.074 & 0.091 & -0.017 \\
average & $(0.048)$ & $(0.047)$ & $(0.068)$ & $(0.046)$ \\
\hline
\end{tabular}

Panel 3: Results for workplace at 0.75 quantile of the distribution of predicted benefits of teams to financial performance; that is, the 0.75 quantile of (Effect A3 - Effect A1).

\begin{tabular}{l|c|c|c|c}
\hline $\begin{array}{l}\text { Financial } \\
\text { performance is ... }\end{array}$ & All Teams & $\begin{array}{c}\text { Autonomous } \\
\text { Teams }\end{array}$ & $\begin{array}{c}\text { Non-Autonomous } \\
\text { Teams }\end{array}$ & Difference \\
\hline average or below & $-0.263^{* *}$ & $-0.269^{* *}$ & $-0.226^{*}$ & -0.043 \\
$(0.100)$ & $(0.099)$ & $(0.120)$ & $(0.068)$ \\
\hline better than average & 0.137 & 0.138 & 0.129 & 0.010 \\
$(0.112)$ & $(0.112)$ & $(0.119)$ & $(0.050)$ \\
\hline A lot better than & $0.126^{* *}$ & $0.131^{* *}$ & 0.097 & 0.034 \\
average & $(0.052)$ & $(0.053)$ & $(0.082)$ & $(0.066)$ \\
\hline
\end{tabular}

Notes: Cell entries denote the effect of team production on the probability that financial performance is at or below, better than, or a lot better than the industry average. That is, for the first three columns, cell entries display the change in the predicted probability that financial performance is [row heading] for the industry, given that [column heading] are used. The fourth column is the second less the third. Standard errors from the parametric bootstrap (100 replications) are in parentheses. * and $* *$ denote statistical significance at the $10 \%$ and $5 \%$ levels, respectively. 
Table 10

Effect of Team Production on Financial Performance of Selected Workplaces (Full Sample)

Panel 1: Results for workplace at the 0.25 quantile of the distribution of predicted benefits of teams to financial performance; that is, the 0.25 quantile of (Effect A3 - Effect A1).

\begin{tabular}{l|c|c|c|c}
\hline Financial performance is & All Teams & Autonomous Teams & $\begin{array}{c}\text { Non-Autonomous } \\
\text { Teams }\end{array}$ & Difference \\
\hline average or below & 0.085 & 0.090 & 0.080 & 0.010 \\
\hline better than average & -0.015 & -0.011 & -0.020 & 0.008 \\
\hline a lot better than average & -0.070 & -0.079 & -0.061 & -0.018 \\
\hline
\end{tabular}

Panel 2: Results for workplace at the median of the distribution of predicted benefits of teams to financial performance; that is, the median of (Effect A3 - Effect A1).

\begin{tabular}{l|c|c|c|c}
\hline $\begin{array}{l}\text { Financial performance is } \\
\ldots\end{array}$ & All Teams & Autonomous Teams & $\begin{array}{c}\text { Non-Autonomous } \\
\text { Teams }\end{array}$ & Difference \\
\hline average or below & -0.048 & -0.022 & -0.058 & 0.035 \\
\hline better than average & 0.044 & 0.060 & 0.037 & 0.022 \\
\hline a lot better than average & 0.004 & -0.037 & 0.020 & -0.058 \\
\hline
\end{tabular}

Panel 3: Results for workplace at 0.75 quantile of the distribution of predicted benefits of teams to financial performance; that is, the 0.75 quantile of (Effect A3 - Effect A1).

\begin{tabular}{l|c|c|c|c}
\hline Financial performance is & All Teams & Autonomous Teams & $\begin{array}{c}\text { Non-Autonomous } \\
\text { Teams }\end{array}$ & Difference \\
\hline average or below & -0.198 & -0.193 & -0.203 & 0.010 \\
\hline better than average & 0.122 & 0.128 & 0.117 & 0.011 \\
\hline a lot better than average & 0.075 & 0.064 & 0.086 & -0.021 \\
\hline
\end{tabular}

Notes: The estimation sample for this table includes all workplaces, regardless of their interpretation of financial performance. $\mathrm{N}=1739$. Cell entries denote the effect of team production on the probability that financial performance is at or below, better than, or a lot better than the industry average. That is, for the first three columns, cell entries display the change in the predicted probability that financial performance is [row heading] for the industry, given that [column heading] are used. The fourth column is the second less the third. Standard errors were not computed. 
Table 11: Estimates from "Non-Structural" Teams Model (Imposing $\boldsymbol{\Sigma}=\mathbf{I}$ )

\begin{tabular}{|c|c|c|c|c|}
\hline & $\begin{array}{c}\text { FINPER* } \\
(T E A M S=1)\end{array}$ & $\begin{array}{c}\text { FINPER* } \\
(T E A M S=0)\end{array}$ & $T E A M S^{*}$ & $A U T O *$ \\
\hline AUTO (1) & $\begin{array}{l}-0.020 \\
(0.080) \\
\end{array}$ & $\bullet$ & $\bullet$ & $\bullet$ \\
\hline Single-Establishment Firm & $\begin{array}{c}0.071 \\
(0.114)\end{array}$ & $\begin{array}{l}-0.172 \\
(0.432)\end{array}$ & $\begin{array}{c}-0.339 \\
(0.183)^{*}\end{array}$ & $\begin{array}{c}-0.366 \\
(0.185)^{*} \\
*\end{array}$ \\
\hline Establishment Size & $\begin{array}{c}-0.003 \\
(0.010) \\
\end{array}$ & $\begin{array}{c}0.054 \\
(0.059) \\
\end{array}$ & $\begin{array}{c}0.031 \\
(0.018)^{*}\end{array}$ & $\begin{array}{c}-0.014 \\
(0.012) \\
\end{array}$ \\
\hline Fraction of Part Time Workers & $\begin{array}{c}0.250 \\
(0.202) \\
\end{array}$ & $\begin{array}{c}-0.208 \\
(0.580) \\
\end{array}$ & $\begin{array}{c}0.135 \\
(0.232) \\
\end{array}$ & $\begin{array}{c}-0.090 \\
(0.158) \\
\end{array}$ \\
\hline Temporary Workers & $\begin{array}{c}0.025 \\
(0.087) \\
\end{array}$ & $\begin{array}{c}0.132 \\
(0.363) \\
\end{array}$ & $\begin{array}{c}0.273 \\
(0.164)^{*}\end{array}$ & $\begin{array}{c}-0.249 \\
(0.138)^{*}\end{array}$ \\
\hline Fixed Term Workers Under One Year & $\begin{array}{c}-0.014 \\
(0.093) \\
\end{array}$ & $\begin{array}{c}-0.406 \\
(0.331) \\
\end{array}$ & $\begin{array}{c}0.213 \\
(0.141)\end{array}$ & $\begin{array}{c}0.004 \\
(0.099)\end{array}$ \\
\hline Fixed Term Workers Over One Year & $\begin{array}{c}0.123 \\
(0.131)\end{array}$ & $\begin{array}{l}-0.458 \\
(0.469)\end{array}$ & $\begin{array}{c}0.230 \\
(0.180)\end{array}$ & $\begin{array}{c}0.356 \\
(0.164)^{*} \\
*\end{array}$ \\
\hline Union Workers & $\begin{array}{c}0.084 \\
(0.113) \\
\end{array}$ & $\begin{array}{c}0.162 \\
(0.372) \\
\end{array}$ & $\begin{array}{c}0.158 \\
(0.136) \\
\end{array}$ & $\begin{array}{c}0.059 \\
(0.105) \\
\end{array}$ \\
\hline Private Sector Franchise & $\begin{array}{c}0.124 \\
(0.389) \\
\end{array}$ & $\begin{array}{c}-3.692 \\
(1.966)^{*}\end{array}$ & $\begin{array}{c}0.571 \\
(1.632) \\
\end{array}$ & $\begin{array}{c}-0.437 \\
(0.474) \\
\end{array}$ \\
\hline Private Sector Non-Franchise & $\begin{array}{c}0.063 \\
(0.164) \\
\end{array}$ & $\begin{array}{c}0.292 \\
(0.569) \\
\end{array}$ & $\begin{array}{c}0.044 \\
(0.202) \\
\end{array}$ & $\begin{array}{l}-0.019 \\
(0.167) \\
\end{array}$ \\
\hline Alternative Private Sector Franchise & $\begin{array}{c}-0.055 \\
(0.462) \\
\end{array}$ & $\begin{array}{c}1.167 \\
(6.049) \\
\end{array}$ & $\begin{array}{l}-0.101 \\
(1.546) \\
\end{array}$ & $\begin{array}{l}-0.480 \\
(0.672) \\
\end{array}$ \\
\hline $\begin{array}{l}\text { Alternative Private Sector Non- } \\
\text { Franchise }\end{array}$ & $\begin{array}{l}-0.205 \\
(0.195) \\
\end{array}$ & $\begin{array}{c}0.781 \\
(0.741) \\
\end{array}$ & $\begin{array}{c}0.115 \\
(0.234)\end{array}$ & $\begin{array}{c}0.265 \\
(0.208) \\
\end{array}$ \\
\hline Financial Participation & $\begin{array}{c}0.260 \\
(0.155)^{*}\end{array}$ & $\begin{array}{c}0.012 \\
(0.403)\end{array}$ & & \\
\hline Owner Manager & $\begin{array}{c}0.078 \\
(0.150) \\
\end{array}$ & $\begin{array}{l}-0.370 \\
(0.540) \\
\end{array}$ & & \\
\hline Foreign Owned & $\begin{array}{l}-0.195 \\
(0.149) \\
\end{array}$ & $\begin{array}{l}-0.405 \\
(0.442)\end{array}$ & & \\
\hline Operation Over Five Years & $\begin{array}{c}0.016 \\
(0.128) \\
\end{array}$ & $\begin{array}{c}0.423 \\
(0.551) \\
\end{array}$ & & \\
\hline Multi-skilling & $\begin{array}{c}0.025 \\
(0.025) \\
\end{array}$ & $\begin{array}{l}-0.005 \\
(0.080) \\
\end{array}$ & & \\
\hline Number of Recognized Unions & $\begin{array}{c}-0.101 \\
(0.057)^{*}\end{array}$ & $\begin{array}{l}-0.032 \\
(0.143)\end{array}$ & & \\
\hline Induction Training & $\begin{array}{l}-0.096 \\
(0.116) \\
\end{array}$ & $\begin{array}{l}-0.508 \\
(0.427) \\
\end{array}$ & & \\
\hline Off-Site Training & $\begin{array}{c}0.046 \\
(0.025)^{*} \\
\end{array}$ & $\begin{array}{l}-0.013 \\
(0.077) \\
\end{array}$ & & \\
\hline Just-in-Time & $\bullet$ & $\bullet$ & $\begin{array}{c}0.315 \\
(0.162)^{*}\end{array}$ & $\bullet$ \\
\hline Information & $\bullet$ & $\bullet$ & $\bullet$ & $\begin{array}{c}0.104 \\
(0.059) * \\
\end{array}$ \\
\hline Incentive Alignment & $\bullet$ & $\bullet$ & $\bullet$ & $\begin{array}{c}-0.245 \\
(0.107)^{*} \\
*\end{array}$ \\
\hline
\end{tabular}




\begin{tabular}{l|c|c|c|c}
\hline Decisions & $\bullet$ & $\bullet$ & $\bullet$ & $\begin{array}{c}0.074 \\
(0.058)\end{array}$ \\
\hline Work at Home & $\bullet$ & $\bullet$ & $\begin{array}{c}-0.136 \\
(0.076)^{*}\end{array}$ \\
\hline \multirow{2}{*}{ Constant } & -0.025 & -0.053 & 0.705 & 0.931 \\
& $(0.295)$ & $(1.058)$ & $(0.301)^{*}$ & $(0.556)^{*}$ \\
\hline \hline & & 1.221 & \\
\end{tabular}

Note: Standard errors from the parametric bootstrap are in parentheses and are based on 100 bootstrap replications. See

Appendix for details. * and ** indicate significance at the $10 \%$ and 5\% levels, respectively. Sample size is 889 
Table 12

"Non-Structural" Effect of Team Production on Financial Performance of Selected Workplaces

Panel 1: Results for Workplace at the 0.25 quantile of the distribution of predicted benefits of teams to financial performance; that is, the 0.25 quantile of (Effect A3 - Effect A1).

\begin{tabular}{l|c|c|c|c}
\hline $\begin{array}{l}\text { Financial } \\
\text { performance is ... }\end{array}$ & All Teams & $\begin{array}{c}\text { Autonomous } \\
\text { Teams }\end{array}$ & $\begin{array}{c}\text { Non-Autonomous } \\
\text { Teams }\end{array}$ & Difference \\
\hline average or below & 0.049 & 0.052 & 0.044 & 0.008 \\
$(0.056)$ & $(0.057)$ & $(0.058)$ & $(0.030)$ \\
\hline better than average & -0.015 & -0.016 & -0.013 & -0.003 \\
& $(0.027)$ & $(0.027)$ & $(0.029)$ & $(0.010)$ \\
\hline a lot better than & -0.034 & -0.036 & -0.031 & -0.005 \\
average & $(0.048)$ & $(0.050)$ & $(0.049)$ & $(0.021)$ \\
\hline
\end{tabular}

Panel 2: Results for workplace at the median of the distribution of predicted benefits of teams to financial performance; that is, the median of (Effect A3 - Effect A1).

\begin{tabular}{l|c|c|c|c}
\hline $\begin{array}{l}\text { Financial } \\
\text { performance is ... }\end{array}$ & All Teams & $\begin{array}{c}\text { Autonomous } \\
\text { Teams }\end{array}$ & $\begin{array}{c}\text { Non-Autonomous } \\
\text { Teams }\end{array}$ & Difference \\
\hline average or below & $-0.111^{*}$ & $-0.108^{*}$ & $-0.116^{* *}$ & 0.008 \\
$(0.059)$ & $(0.062)$ & $0.059)$ & $(0.029)$ \\
\hline better than average & 0.068 & $0.066^{*}$ & $0.070^{*}$ & -0.004 \\
$(0.037)^{*}$ & $(0.037)$ & $(0.037)$ & $(0.009)$ \\
\hline a lot better than & 0.044 & 0.042 & 0.046 & -0.004 \\
average & $(0.031)$ & $(0.034)$ & $(0.033)$ & $(0.023)$ \\
\hline
\end{tabular}

Panel 3: Results for workplace at 0.75 quantile of predicted benefits of teams to financial performance; that is, the 0.75 quantile of (Effect A3 - Effect A1).

\begin{tabular}{l|c|c|c|c}
\hline $\begin{array}{l}\text { Financial } \\
\text { performance is ... }\end{array}$ & All Teams & $\begin{array}{c}\text { Autonomous } \\
\text { Teams }\end{array}$ & $\begin{array}{c}\text { Non-Autonomous } \\
\text { Teams }\end{array}$ & Difference \\
\hline average or below & $-0.233^{* *}$ & $-0.230^{* *}$ & $-0.237^{* *}$ & 0.007 \\
$(0.076)$ & $(0.078)$ & $0.077)$ & $(0.029)$ \\
\hline better than average & 0.091 & 0.090 & 0.091 & -0.001 \\
& $(0.059)$ & $(0.059)$ & $(0.060)$ & $(0.008)$ \\
\hline a lot better than & $0.142^{* *}$ & $0.140^{* *}$ & $0.146^{* *}$ & -0.006 \\
average & $(0.037)$ & $(0.041)$ & $(0.036)$ & $(0.023)$ \\
\hline
\end{tabular}

Notes: Cell entries denote the effect of team production on the probability that financial performance is at or below, better than, or a lot better than the industry average. That is, for the first three columns, cell entries display the change in the predicted probability that financial performance is [row heading] for the industry, given that [column heading] are used. The fourth column is the second less the third. Standard errors from the parametric bootstrap (100 replications) are in parentheses. * and ** denote statistical significance at the $10 \%$ and $5 \%$ levels, respectively. The results of this table were derived by imposing the constraints $\boldsymbol{\Sigma}=\mathbf{I}$ in estimation. 
Figure 1: Predicted Effects of Teams on Financial Performance ( $\mathrm{N}=889$ establishments)

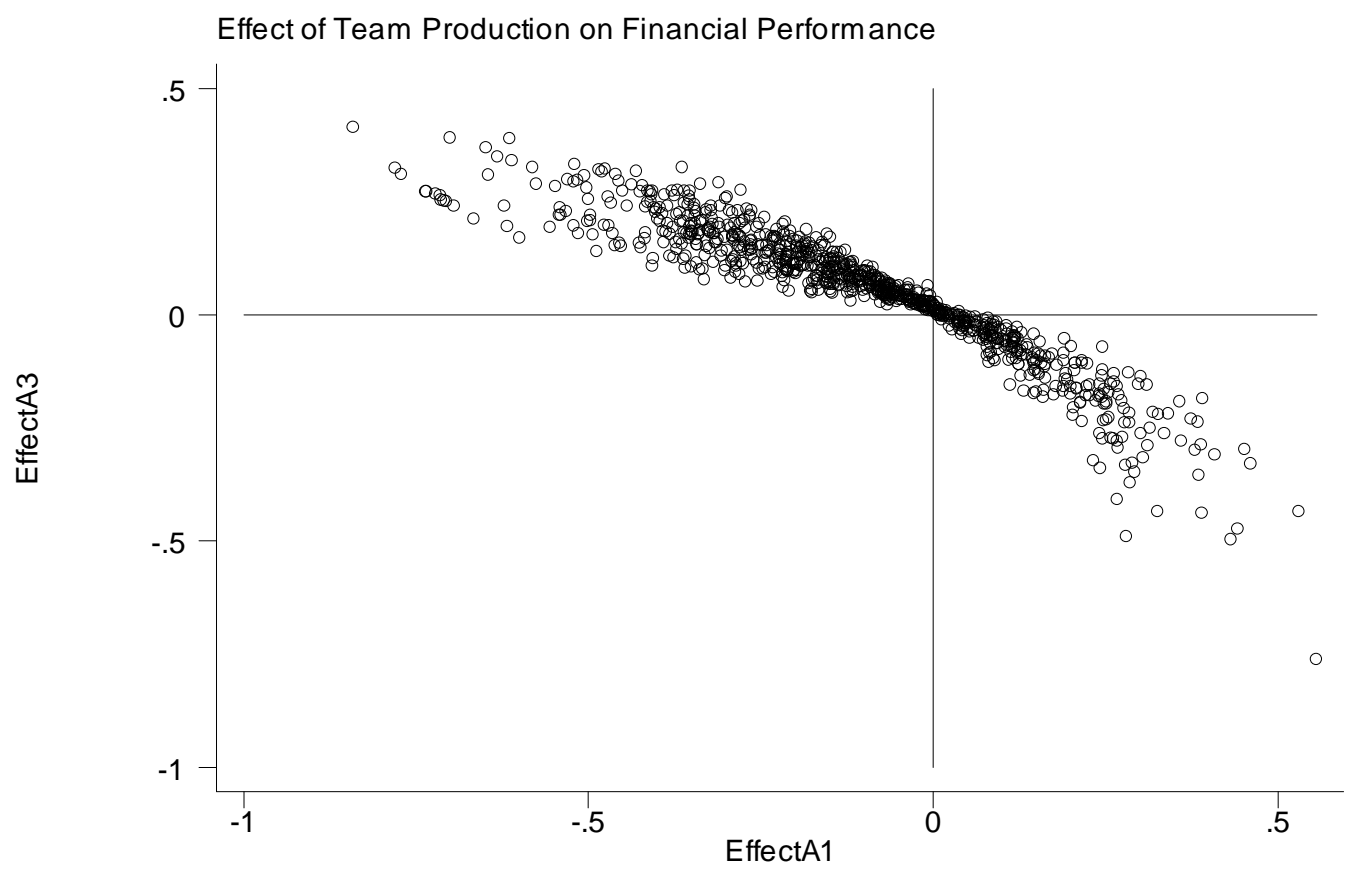

Notes: The axes are defined as follows:

EffectA3 $=\operatorname{Prob}($ FINPER $=3 \mid$ TEAMS $=1)-\operatorname{Prob}($ FINPER $=3 \mid$ TEAMS $=0)$

EffectA $1=\operatorname{Prob}($ FINPER $=1 \mid$ TEAMS $=1)-\operatorname{Prob}($ FINPER $=1 \mid$ TEAMS $=0)$

FINPER $=3$ is the highest financial performance category, indicating performance "a lot better than average" for the industry. FINPER $=1$ is the lowest category, indicating performance at or below the industry average. Appendix states the formulae for computing Effects A1 and A3. 
